\title{
FORAMINIFEROS PLANCTONICOS DURANTE EL NIÑO 1997-98 DEL AREA DE COQUIMBO $\left(30^{\circ} \mathrm{S} ; 73^{\circ} \mathrm{W}\right), \mathrm{CHILE}^{*}$
PLANKTONIC FORAMINIFERA DURING EL NIÑO 1997-98 OFF COQUIMBO $\left(30^{\circ} \mathrm{S} ; 73^{\circ} \mathrm{W}\right)$, CHILE

\author{
Cecilia Coloma ${ }^{1,2}$, Margarita Marchant ${ }^{2}$ \& Dierk Hebbeln. ${ }^{3}$ \\ ${ }^{1}$ Candidata a Magíster en Ciencias mención Zoología, Universidad de Concepción. \\ ${ }^{2}$ Departamento de Zoología, Universidad de Concepción, Casilla 160-C, Concepción, Chile. \\ ${ }^{3}$ Departamento de Geología, Universidad de Bremen, Postfach 330440, D-28334 Bremen, Germany. \\ *Proyecto Fondecyt Nº1010912 y Proyecto Copas No 150100007
}

\begin{abstract}
RESUMEN
Se estudiaron los foraminíferos planctónicos recientes recolectados con dos trampas de sedimento (CH10-2 y CH11-2) ancladas a una profundidad de $2.300 \mathrm{~m}$ frente a Coquimbo $\left(30^{\circ} \mathrm{S} ; 73^{\circ} \mathrm{W}\right)$, Chile, abarcando un año y medio de muestreo (14 febrero 1997-1 julio 1998), con el objeto de estudiar el evento de El Niño 1997-98 y el estado de conocimiento de la foraminiferofauna del área de Coquimbo. En total se determinaron 26 especies, 6 de ellas propias de aguas cálidas que aparecieron por primera vez en el área de estudio con El Niño 1997-98. Se presenta la revisión taxonómica (sinonimias y combinaciones), caracteres diagnósticos y biología de cada especie, acompañado de una clave específica y microfotografías (SEM).
\end{abstract}

Palabras claves: Foraminíferos planctónicos, Coquimbo, Chile, biodiversidad, taxonomía, nuevos registros, El Niño 1997-98.

\section{ABSTRACT}

Recent planktonic foraminifera from two sediment traps (CH10-2 and $\mathrm{CH} 11-2)$ situated off Coquimbo $\left(30^{\circ} \mathrm{S}\right.$; $73^{\circ} \mathrm{W}$ ), Chile, during one and a half year (14 february 1997- 1 july 1998), were studied. A total of 26 planktic foraminifera species were identified, six are characteristic of warm waters and have appeared for the first time in the study area with El Niño 1997-98. The taxonomic revision (synonymies and combinations), character diagnoses and biology of each species, accompanied by a specific key and microphotographs (SEM), are presented.

Keywords: Planktonic foraminifera, Coquimbo, Chile, biodiversity, taxonomy, new record, El Niño 1997-98. 


\section{INTRODUCCION}

La mayoría de los estudios de foraminíferos recientes en Chile, se refieren principalmente a foraminíferos bentónicos, citando entre éstos a especies planctónicas (D’Orbigny 1839, Brady 1884, Egger 1893, Cushman \& Wickenden 1929, Heron-Allen \& Earland 1932, Bandy \& Rodolfo 1964, Boltovskoy \& Theyer 1970, Zapata \& Varela 1975, Zapata \& Cea 2002). Pocos son los trabajos que se refieren exclusivamente a los foraminíferos planctónicos (Guzmán 1972, Boltovskoy 1976, Zapata \& Castillo 1986, Marchant 1997, Marchant et al. 1998).

El área de estudio, ubicada a la cuadra de Coquimbo $\left(30^{\circ} \mathrm{S} ; 73^{\circ} \mathrm{W}\right)$ (Fig. 1A), se encuentra influenciada por la presencia de aguas subantárticas y subtropicales, caracterizadas por una asociación faunística de foraminíferos planctónicos de Transición (Boltovskoy 1976, Marchant et al. 1998). Se ha estudiado el flujo de foraminíferos en esta zona, bajo la influencia de El Niño 1991-92 y en condiciones normales (Marchant et al. 1998, Hebbeln et al. 2000). Además, esta zona presenta una gran productividad relacionada con los eventos de surgencia, siendo mayor en el período de primavera-verano (Marchant et al. 1998).

El objetivo principal de este trabajo es estudiar el evento El Niño 1997-98, mediante los foraminíferos planctónicos del área de Coquimbo y revisar el estado de conocimiento taxonómico de las especies del área de Coquimbo

\section{MATERIALES Y METODOS}

Se estudiaron las muestras de foraminíferos planctónicos de las trampas de sedimento $\mathrm{CH} 10$ 2 (14 febrero-01 noviembre 1997) y CH11-2 (04 noviembre 1997-01 julio 1998), ubicadas a 150 $\mathrm{km}$ de la costa frente a Coquimbo $\left(30^{\circ} \mathrm{S} ; 73^{\circ} \mathrm{W}\right)$, a $2.300 \mathrm{~m}$ de profundidad, período de tiempo que coincide con el evento El Niño 1997-98.

Cada trampa (Kiel type 230) (Fig. 1B) se equipó con 20 botellas, programadas con un intervalo de tiempo de 12 y 13 días, respectivamente. Las botellas se fijaron con una solución de $3.5 \mathrm{ml}$ de $\mathrm{HgCl}_{2}$ saturado por $100 \mathrm{ml}$ de muestra, para retardar la actividad bacteriana del material recolectado, agregándose además, $20 \mathrm{ml}$ de $\mathrm{NaCl}$ para alcanzar la salinidad de 38-40 psu. Una vez recolectadas las muestras, se les volvió a agregar $\mathrm{HgCl}_{2}(1 \mathrm{ml} / 100 \mathrm{ml}$ de agua de mar) y se almacenaron a $4^{\circ} \mathrm{C}$. Finalmente, las muestras fueron enviadas al Laboratorio de la Universidad de Bremen (Alemania), donde se dividieron en alícuotas iguales de 1/25 (Fisher \& Weber 1991) para diferentes estudios.

Posteriormente, una vez regresadas las muestras destinadas al estudio de foraminíferos planctónicos, en el Laboratorio de Foraminíferos de la Universidad de Concepción, las muestras se lavaron en agua destilada y secaron a una temperatura de $50^{\circ} \mathrm{C}$ y se dividieron en tres fracciones: > $212 \mu \mathrm{m}, 150-212 \mu \mathrm{m}$ y $<150 \mu \mathrm{m}$, siendo pesadas (mg) cada una de ellas. En cada fracción, las especies de foraminíferos planctónicos encontradas fueron identificadas y contabilizadas. En los análisis sólo se consideraron las fracciones $>150 \mu \mathrm{m}$ para evitar errores en la identificación.

La identificación de las especies se basó en las descripciones morfológicas de Kennett \& Srinivasan (1983), Hemleben et al. (1989) y Loeblich \& Tappan (1988). El orden sistemático de las especies se realizó de acuerdo a Decrouez (1989), Cavalier-Smith (1998) y Loeblich \& Tappan (1988). Los nombres específicos fueron revisados en literatura especializada en el tema, se indican sinonimias y combinaciones para cada una de las especies.

Finalmente, se realizaron microfotografías de algunos especímenes de las trampas de sedimento CH5-2, CH8-2, CH10-2 y CH11-2, con microscopio electrónico de barrido (SEM) en el Laboratorio de Microscopía Electrónica de la Universidad de Concepción.

Las especies Globorotalia crassaformis, Globigerinella digitata, Turborotalita quinqueloba, no poseen microfotografías (SEM), por la falta de material y/o fotos defectuosas, precisándose de nuevo material.

Debido a la falta de ejemplares no se depositaron especímenes de 6 especies (Globorotalia crassaformis, G. tumida, G. theyeri, Globigerinoides hexagonus, Globigerinella digitata y Pulleniatina obliquiloculata), en la Colección Científica de la Universidad de Concepción (UCCC). 

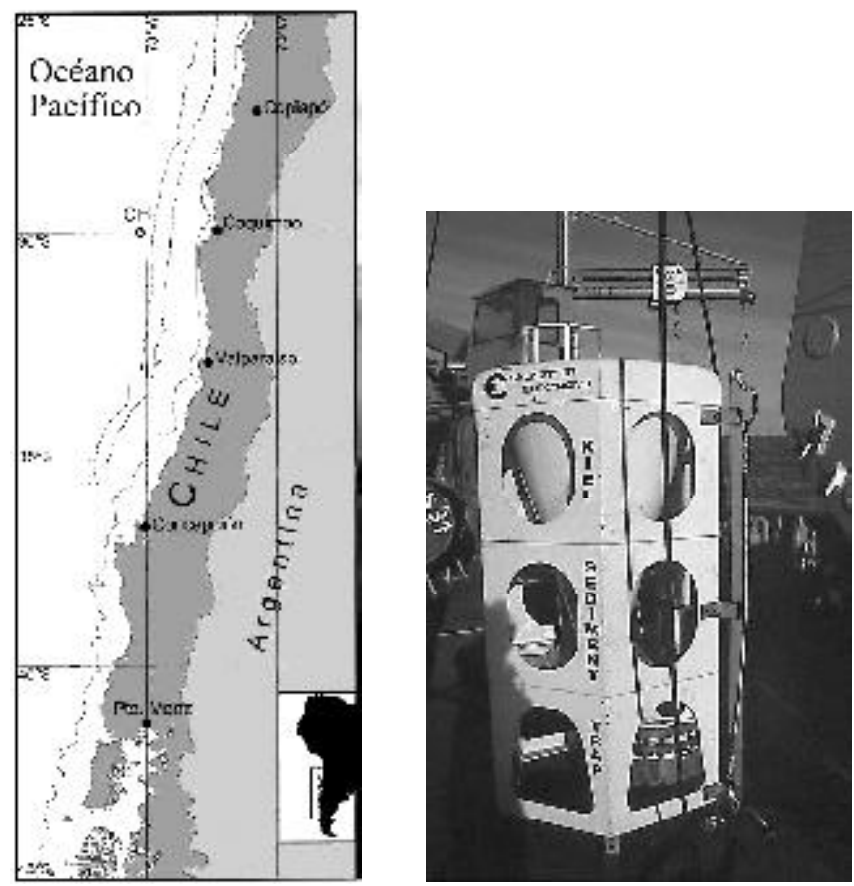

FIGURA 1. A, ubicación geográfica del anclaje de las trampas de sedimento (CH10-2 y CH11-2) indicado con las letras CH frente a Coquimbo, Chile $\left(30^{\circ} \mathrm{S} ; 73^{\circ} \mathrm{W}\right)$ y B, trampa de sedimento Kiel-type.

FIGURE 1. A, Geographic Location of the mooring site the sediments traps (CH10-2 and CH11-2) indicate with the letters $\mathrm{CH}$ off Coquimbo, Chile $\left(30^{\circ} \mathrm{S} ; 7^{\circ} \mathrm{W}\right)$ and B Sediment trap Kiel-type.

\section{RESULTADOS}

\section{For AMiniferofauna}

Se identificó un total de 26 especies de foraminíferos planctónicos (>150 $\mu \mathrm{m})$ pertenecientes a 12 géneros y 6 familias (Lista 1 , Tabla I), cuyos datos de abundancia y frecuencia se presentan en Marchant et al. (In litteralis). Entre éstas, encontramos las especies típicas de la Zona de Transición: Neogloboquadrina pachyderma, Globigerina bulloides, Globigerinita uvula, Globorotalia scitula, Neogloboquadrina dutertrei, Globorotaloides hexagonus y Globigerinoides ruber (Boltovskoy 1976, Marchant et al. 1998), así como, especies propias de aguas cálidas, indicadoras de El Niño en Coquimbo: Globigerinella aequilateralis, Globorotalia crassaformis y Pulleniatina obliquiloculata (Marchant et al. 1998).

Del total de especies encontradas, las más abundantes, que conforman el $81 \%$ de la asociación estudiada, son: $N$. incompta $(41.5 \%)$ Globigerina bulloides (20.5\%), Globigerinella calida (7.9\%), N. pachyderma (7.2\%) y Neogloboquadrina dutertrei (4\%) (Tabla II).

Se registraron por primera vez 7 especies para el área de Coquimbo con El Niño 1997-98: Globigerinoides sacculifer, G. trilobus, Globigerinella digitata, Hastigerina digitata, Globorotalia theyeri y G. tumida (de aguas cálidas) y Globigerinita uvula (especie de aguas frías). De éstas 7 especies, aquellas de aguas cálidas se consideran en este estudio como indicadores de la intensidad de El Niño (al igual que las especies nombradas anteriormente), por ser especies de aguas tropicales (Boltovskoy 1976). 
Lista 1: Taxonomía de las especies de foraminíferos planctónicos encontradas durante El Niño 1997-98 frente a Coquimbo, Chile $\left(30^{\circ} \mathrm{S}\right.$; $\left.73^{\circ} \mathrm{W}\right)$. Basado en Decrouez (1989), CavalierSmith (1998) y Loeblich \& Tappan (1988).

Phylum FORAMINIFERIDA Cavalier-Smith
1998

Suborden GLOBIGERININA Delage \& Hérouard 1896

Superfamilia GLOBOROTALIACEA Cushman 1927.

Familia GLOBOROTALIIDAE Cushman 1927

Género Globorotalia Cushman 1927

G. crassaformis (Galloway \& Wissler 1927)

$G$ inflata (D'Orbigny 1839)

G. menardii (D’Orbigny 1826)

G scitula (Brady 1882)

G. theyeri Fleisher 1974

G. truncatulinoides (D'Orbigny 1839)

G tumida (Brady 1877)

Género Neogloboquadrina Bandy, Frerichs \&Vincent 1967

$N$. dutertrei (D’Orbigny 1865)

$N$. incompta (Cifelli 1961) $(=N$. pachyderma (dex.))

N. pachyderma (Ehrenberg 1861) $(=N$. pachyderma (lev.))

Familia PULLENIATINIDAE Cushman 1927

Género Pulleniatina Cushman 1927

P. obliquiloculata Parker \& Jones 1865

\section{Familia CANDEINIDAE}

Género Tenuitella Fleisher 1974

T. iota (Parker 1962)
Género Globigerinita Brönnimann 1951

G. glutinata (Egger 1893)

G. uvula (Ehrenberg 1861)

Familia CATAPSYDRACIDAE Bolli, Loeblich \& Tappan 1957.

Género Globorotaloides Bolli 1957

G. hexagonus (Natland 1938)

Superfamilia GLOBIGERINACEA Carpenter, Parker \& Jones 1862.

Familia GLOBIGERINIDAE Carpenter, Parker \& Jones 1862.

Género Globigerina d'Orbigny 1826

G. bulloides d'Orbigny 1826

Género Globigerinella Cushman 1927

G. calida (Parker 1962)

G. digitata (Brady 1879)

G. aequilateralis (Brady 1879)

Género Globigerinoides Cushman 1927

G. ruber (d'Orbigny 1839)

G. sacculifer (Brady 1877) (= G. trilobus sacculifer)

G. trilobus (Reuss 1850) (= G. trilobus trilobus)

Género Turborotalita Blow \& Banner 1962

T. quinqueloba (Natland 1938)

T. humilis (Brady 1884)

Género Orbulina d'Orbigny 1839

O. universa d'Orbigny 1839

Familia HASTIGERINIDAE Bolli, Loeblich \& Tappan 1957

Género Hastigerina Thomson 1876

H. digitata (Rhumbler 1911) 
Gayana 69(1), 2005

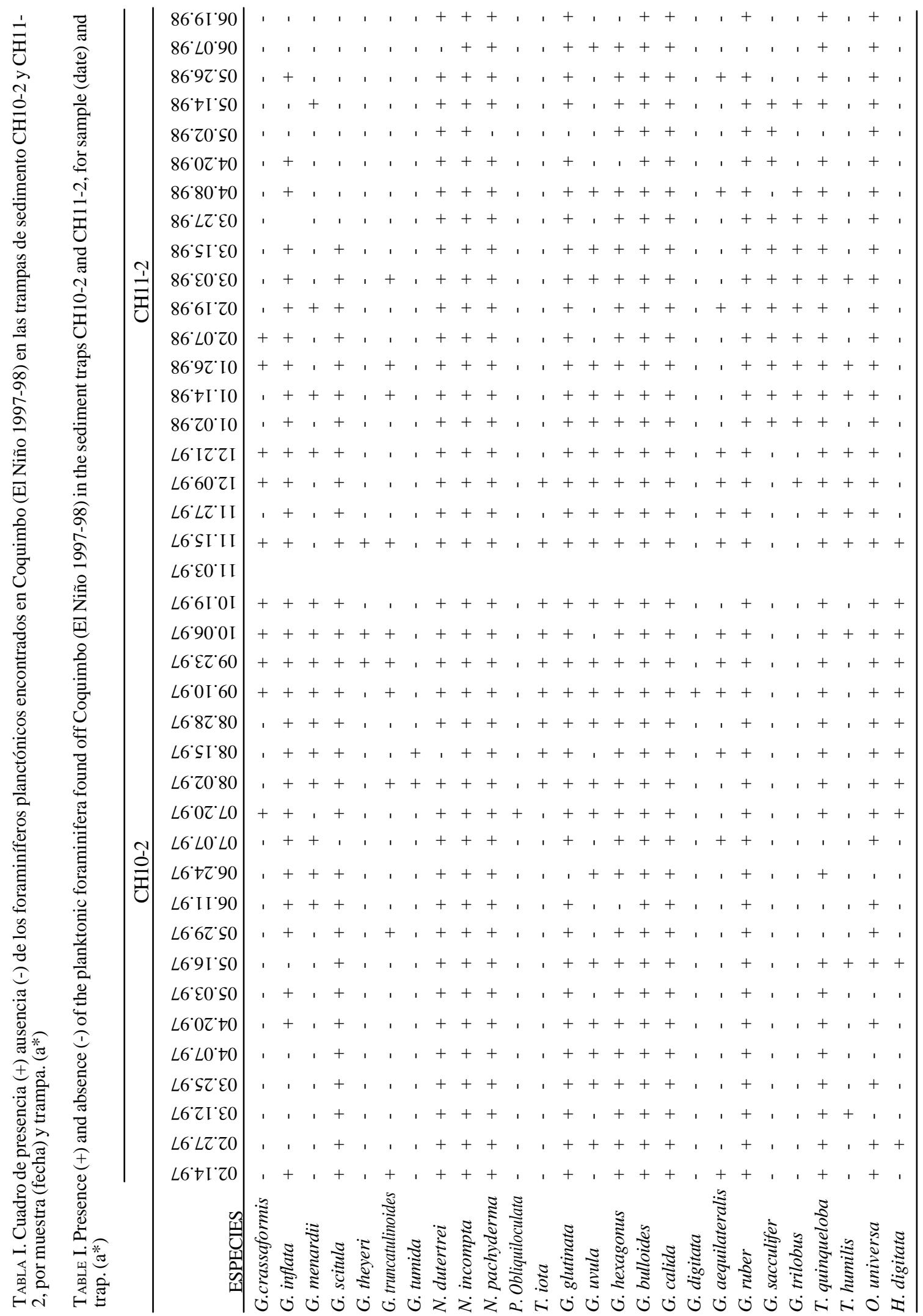


Foraminíferos planctónicos: Coloma, C. ET AL.

TABLA II. Abundancia relativa total de los foraminíferos planctónicos encontrados en el área de Coquimbo durante El Niño 1997-98.

TABLE II. The total relative abundance of the planktonic foraminifera found off Coquimbo during El Niño 1997-98.

\begin{tabular}{lc}
\hline ESPECIES & Abundancia relativa (\%) \\
\hline Globorotalia crassaformis & 0.12 \\
G. inflata & 1.12 \\
G. menardii & 0.31 \\
G. scitula & 1.06 \\
G. theyeri & 0.02 \\
G. truncatulinoides & 0.09 \\
G. tumida & 0.11 \\
Neogloboquadrina dutertrei & 4.00 \\
N. incompta & 41.50 \\
N. pachyderma & 7.18 \\
Pulleniatina obliquiloculata & 0.07 \\
Tenuitella iota & 0.11 \\
Globigerinita glutinata & 3.8 \\
G. uvula & 0.98 \\
Globorotaloides hexagonus & 1.21 \\
Globigerina bulloides & 20.52 \\
Globigerinella calida & .80 \\
G. digitata & 0.004 \\
G. aequilateralis & 0.39 \\
Globigerinoides ruber & 2.73 \\
G. sacculifer & 1.22 \\
G. trilobus & 0.62 \\
Turborotalita quinqueloba & 2.64 \\
T. humilis & 0.05 \\
Orbulina universa & 1.96 \\
Hastigerina digitata & 1.38 \\
\hline TOTAL ABUNDANCIA & $\sim 100$ \\
\hline
\end{tabular}

FIGURA 2. Abundancia relativa de las 5 especies más abundantes durante El Niño 1997-98.

FIGURE 2. Relative abundance of the more abundant species during El Niño 1997-98.

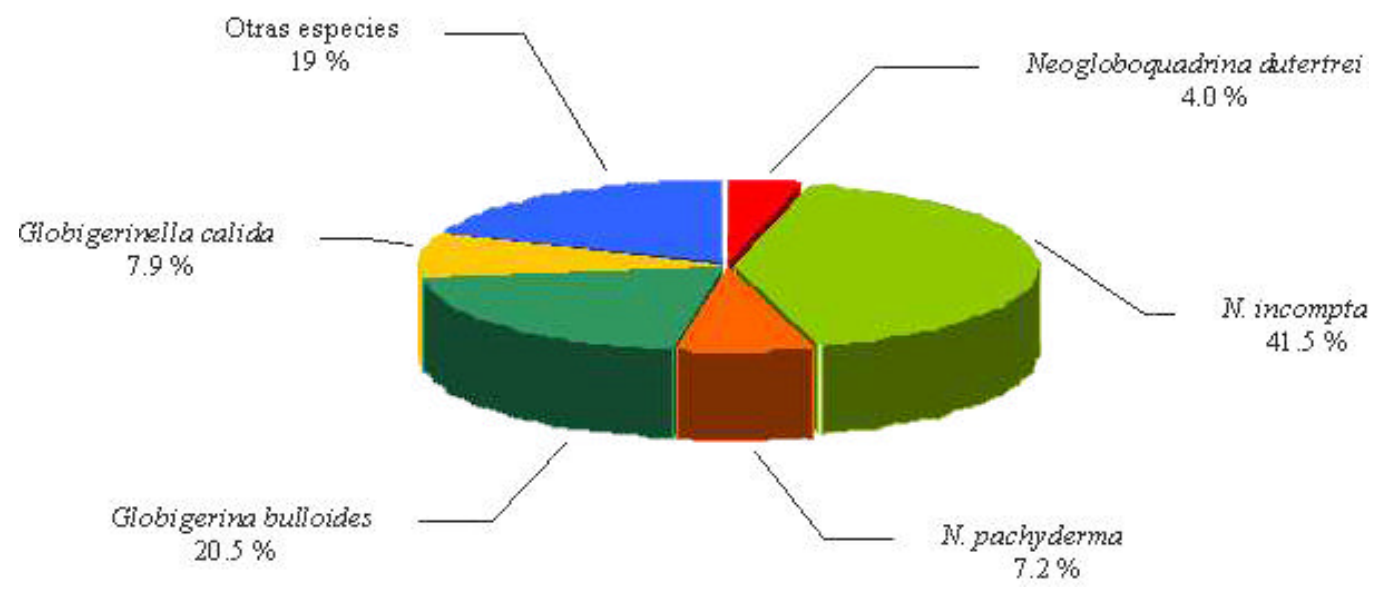




\section{CARACTERIZACION DE LAS ESPECIES EN- CONTRADAS}

Se da a conocer la taxonomía (sinonimias y nuevas combinaciones), caracteres diagnósticos, biología conocida e ilustración de las especies registradas durante este estudio (ver Lista 1). Se indica el número de registro de algunos especímenes ingresados a la Colección Científica de la Universidad de Concepción, Concepción-Chile (UCCC).

Finalmente, se entrega una clave dicotómica para las especies de foraminíferos planctónicos registrados.

Globorotalia crassaformis (Galloway \& Wissler 1927)

Globigerina crassaformis Galloway \& Wissler 1927 : 41, lám. 7, fig. 12.

Globorotalia crassula Cushman et al.1930: 77, lám. 7, figs. 1a-c.

Globorotalia crassaformis (Galloway \& Wissler). Parker 1962: 235, lám. 4, figs. 17-18, 20-21; Jenkins 1964: 25, text-fig. 1 (list); Boltovskoy 1976: 230; 1981: 341, 350, fig. 168 (40a-c); Hemleben et al. 1989: 23, fig. 2.5 a-c; Zapata \& Cea 2002: 65, 70, lám. 3, figs. 3-4-5.

Globorotalia puncticulata (Deshayes). Le Roy 1964: 454-F, lám. 9, figs. 11-13.

Globorotalia (Globorotalia) crassaformis (Galloway \& Wissler). Jenkins 1971: 86, lám. 4, figs. 105-107. Globorotalia crotonensis Conato \& Follador 1967. Hemleben et al. 1989: 23.

Globorotalia (Truncorotalia) crassaformis (Galloway \& Wissler). Kennett \& Srinivasan 1983: 146, lám. 34, figs. 6-8.

Material estudiado: Trampa CH10-2, muestras 13, 17-20; trampa CH11-2, muestras 2, 4, 5, 8, 9; total ejemplares: 16 .

CARACTERÍsTICA PRINCIPAL: Conchilla trocoespiral, plano-cónica, con enrollamiento levógiro, superficie lisa o levemente pustulosa, con poros muy pequeños, carece de espinas, margen periférico con quilla (en juveniles inconspicua), largo máximo $0.65 \mathrm{~mm}$. Cámaras de forma cónica angulosas, última vuelta con 5-6 cámaras en juveniles y 4-5 en adultos. Abertura extraumbilical con labio (Boltovskoy 1981).
Otros Aspectos: Bandy \& Rodolfo (1964), Boltovskoy \& Watanabe (1975) y por Marchant et al. (1998) han mencionado a G. crassaformis, pero no la describieron ni la figuraron.

G. crassaformis vive a grandes profundidades en aguas intermedias. Es parte de la fauna de agua cálida y templado-cálida de todos los océanos (Boltovskoy \& Wright 1976, Boltovskoy 1981). El límite de tolerancia de temperatura $\left(\mathrm{TSM}^{\circ} \mathrm{C}\right)$ para esta especie está entre los 6 y $27^{\circ} \mathrm{C}$ (Boltovskoy \& Wright 1976). En el área de estudio apareció con anomalías positivas de temperatura (Marchant et al. 1998).

\section{Globorotalia inflata (d'Orbigny 1839) Figura 3 (Figs. 3.1-3.5)}

Globigerina inflata d'Orbigny 1839. Barker-Webb \& Berthelot, Hist. Nat. Iles Canaries "Foraminiferes" 2(2): 134, lám. 2, figs. 7-9 (fide Jenkins 1971); Brady 1884: 601, lám. 79, figs. 8-10; Cushman \& Wickenden 1929: 13, lám. 5, fig. 8; Heron-Allen \& Earland 1932: 176.

Globorotalia (Globoconella) inflata (d'Orbigny). Kennett \& Srinivasan 1983: 118, lám. 27, figs. 7-9. Globorotalia puncticulata (Deshayes). In Dondi 1963, Boll. Soc. Geol. Ital. 81(4): 174, fig. 50 (list.) (fide Jenkins 1971).

Globorotalia (Turborotalia) inflata (d'Orbigny). Jenkins 1971: 116, lám. 11, figs. 282-287.

Globorotalia inflata (d'Orbigny). Finlay 1939: 530; Finlay \& Marwick 1940: 125; Finlay 1947: 352; Hornibrook 1958: 31, tabla 2; Parker 1962: 236, lám. 5, figs. 6-9; Jenkins 1964: 25, text-fig. 1 (list); McInnes 1965: 104, fig. 2, $\mathrm{n}^{\mathrm{o}}$. 2a-c; fig. 3, no $7 \mathrm{a}-\mathrm{c}$; Boltovskoy 1976: 230; 1981: 341, 350, fig. 168 (41ac), Zapata \& Castillo 1986: 56, figs. 18-20; Hemleben et al. 1989: 23, fig. 2.5 f-h; Zapata \& Cea 2002: 65, 71, lám. 4, figs. 3-5.

Material estudiado: Trampa CH10-2, muestras 1,6, 7, 9-20; trampa CH11-2, muestras 2-12, 14, 15, 18; total ejemplares: 211

Museo: UCCC No 26939, 10 ejemplares de CH10-2 $\mathrm{N}^{\mathrm{o}} 17>212 \mu \mathrm{m}$.

CARACTERÍstica PRINCIPAL: Conchilla trocoespiral, plana-cónica, redondeada, con enrollamiento 
levógiro, superficie lisa; lado dorsal plano, ventral convexo; zona abertural pustulosa, con poros muy pequeños, carece de espinas, margen periférico redondeado, largo máximo $0.65 \mathrm{~mm}$. Cámaras hemiesféricas, infladas, última vuelta con 5 cámaras en juveniles y 4 en adultos. Abertura umbilical extraumbilical grande con reborde (Boltovskoy 1981).

OTROS ASPECTOS: Esta especie también está citada por Bandy \& Rodolfo (1964) y Marchant et al. (1998) en aguas chilenas.

Especie dominante en aguas temperadas (> 30\%), pudiéndose encontrar tanto en aguas subtropicales como frías pero en menor porcentaje $(<4 \%)$ (Boltovskoy et al. 1996), Bé \& Tolderlund (1971), consideran a $G$. inflata como especie indicadora de la Zona de Transición. Especie de aguas profundas, vive en la zona fótica de juvenil, pero desciende a profundidades mayores de los $500 \mathrm{~m}$ al madurar (Bé \& Tolderlund 1971, Bé 1977). El límite de tolerancia de temperatura $\left(\mathrm{TSM}^{\circ} \mathrm{C}\right)$ para esta especie está entre los -0.7 y los $27^{\circ} \mathrm{C}$ (Boltovskoy \& Wright 1976). Se alimenta de fitoplancton en la zona fótica (Boltovskoy 1981).

\section{Globorotalia menardii (d'Orbigny 1826)}

Figura 4 (Figs. 4.1-4.4)

Rotalia menardii d'Orbigny 1826 Ann. Sci. Nat., ser. 1, 7(26): 273, Modéles $N^{\circ} 10$ (nomen nudum) (fide Jenkins 1971); Parker, Jones \& Brady 1865, Ann. Mag. Nat. Hist., ser. 3, 16: 20, lám. 3, fig. 81 fide Jenkins 1971); Banner \& Blow 1960b: 31, lám. 6, fig. 2a-c (lectotype).

Rotalia (Rotalia) menardii d'Orbigny 1826: 273, Modéles no. 10 (nomen nudum) (fide Jenkins 1971). Rotalia cultrata (Baley 1851). Banner \& Blow 1960b: 34, lám. 6, fig. 1a-c.

Globorotalia menardii (d'Orbigny) subsp. menardii. Jenkins 1960: 362, lám. 4, fig. 9a-c.

Globorotalia (Menardella) menardii (d'Orbigny). Kennett \& Srinivasan 1983: 124, lám. 28, fig. 2, lám. 29, figs. 1-3.

Globorotalia (Globorotalia) menardii (d'Orbigny). Jenkins 1971: 90, lám. 6, figs. 135-137.

Globorotalia menardii (d'Orbigny). Boltovskoy 1976: 230; Boltovskoy 1981: 341, 350, fig. 168 (35ac, 36, 37); Hemleben et al. 1989: 23, 24, fig. 2.5 f-h.
Material estudiado: Trampa CH10-2, muestras 1012, 14-20; trampa CH11-2, muestras 5, 7, 10, 17; total ejemplares: 82

Museo: UCCC No26948, 2 ejemplares de CH11-2 $\mathrm{N}^{\mathrm{o}} 10>212 \mu \mathrm{m}$.

CARACTERÍSTICA PRINCIPAL: Conchilla trocoespiral muy aplanada, de contorno lobulado, paredes vítreas, con enrollamiento levógiro, superficie lisa, pustulosa en la zona abertural, con poros muy pequeños, carece de espinas, margen periférico con quilla, largo máximo $1.5 \mathrm{~mm}$. Cámaras angulosas romboidales, última vuelta con 5-6 cámaras. Abertura extraumbilical, con labio (Boltovskoy 1981).

Otros Aspectos: Se le considera como una especie tropical-subtropical, vive preferentemente en aguas subsuperficiales bajo los $50 \mathrm{~m}$ y probablemente desciende hasta profundidades batipelágicas al final de su ontogenia (Bé \& Tolderlund 1971, Bé 1977). Según Boltovskoy (1981), prefiere una profundidad bajo la zona fótica (e.g. 200-400 m).

El límite de tolerancia de temperatura $\left(\mathrm{TSM}^{\circ} \mathrm{C}\right)$ para esta especie está entre los 10.8 y $30^{\circ} \mathrm{C}$ (Boltovskoy \& Wright 1976). Bé \& Tolderlund (1971) indican que se le encuentra en un rango de temperatura superficial entre $\operatorname{los} 16^{\circ}$ a $30^{\circ} \mathrm{C}$ y que es más abundante entre $\operatorname{los} 20^{\circ}$ a $25^{\circ} \mathrm{C}$.

\section{Globorotalia scitula (Brady 1882)}

Figura 5 (Figs. 5.1-5.5)

Pulvinulina scitula Brady 1882: 761; Banner \& Blow 1960a: 27, lám. 5, fig. 5 (lectotipo).

Globorotalia bermudezi Rögl \& Bolli 1973. In Hemleben et al. 1989: 25.

Globorotalia (Hirsutella) scitula (Brady). Kennett \& Srinivasan 1983: 134, lám. 31, figs. 1, 3-5.

Globorotalia scitula scitula (Brady). Blow 1959: 219, lám. 19, fig. 126a-c.

Globorotalia scitula gigantea Blow 1959: 220, lám. 16, fig. $127 \mathrm{a}-\mathrm{c}$.

Globorotalia scitula (Brady). Parker 1962: 238, lám. 6, figs. 4-6.

Globorotalia (Turborotalia) scitula (Brady). Jenkins 1971: 131, lám.13, figs. 371-373.

Globorotalia scitula (Brady). Boltovskoy \& Theyer 1970: 371, lám. 6, fig. 10; Boltovskoy 1976: 231; 
1981: 341, 350, fig. 168 (45a-c, 46); Zapata \& Castillo 1986: 57, figs. 21-22; Hemleben et al. 1989: 25, fig. $251-m$.

Material estudiado: Trampa CH10-2, muestras 120; Trampa CH11-2, muestras 2-12; total ejemplares: 321.

Museo: UCCC N²6949, 4 ejemplares de CH11-2 $\mathrm{N}^{\mathrm{o}} 2>212 \mu \mathrm{m}$.

CARACTERÍstica PRINCIPAL: Conchilla trocoespiral aplanada biconvexa, enrollamiento dextral o levógiro, superficie lisa parcialmente pustulosa, con poros medianos, carece de espinas, margen periférico redondeado, paredes lisas, largo máximo $0.65 \mathrm{~mm}$. Cámaras angulosas romboidales, última vuelta con 5-6 cámaras. Abertura extraumbilical con labio (Boltovskoy 1981).

Otros Aspectos: Especie de aguas profundas, abundante en zonas temperadas cálidas a subtropicales intermedias (Boltovskoy 1981). El límite de tolerancia de temperatura $\left(\mathrm{TSM}^{\circ} \mathrm{C}\right)$ para esta especie está entre los 8 y $22.5^{\circ} \mathrm{C}$ (Boltovskoy \& Wright 1976).

\section{Globorotalia theyeri Fleisher 1974}

Figura 6 (Figs. 6.1-6.4)

Globorotalia (Hirsutella) theyeri Fleisher 1974 In Kennett \& Srinivasan 1983:140, lám. 31, fig. 2; lám 33, figs 1-3.

Globorotalia theyeri Fleisher 1974 In Hemleben et al. 1989: 25, fig. 2.6 a-c.

Material estudiado: Trampa CH10-2, muestras 1819; trampa CH11-2, muestra 2; total ejemplares: 8.

CARACTERÍSTICA PRINCIPAL: Conchilla alargada, plana convexa a desigualmente biconvexa, margen ecuatorial lobulado con cámaras translúcidas en la última vuelta; margen axial agudo, con quilla periférica discontinua, delgado; última vuelta con cuatro a cinco cámaras, aumentando moderadamente a rápidamente en tamaño; suturas espirales fuertemente recurvadas, deprimidas, en lado umbilical suavemente convexa, a radial, deprimido; superficie finamente y uniformemente perforada; umbilico grande, profundo; abertura interiomarginal, umbilical extraumbilical un arco bajo orillado por un labio distinto pero delgado (Kennett \& Srinivasan 1983).

Otros Aspectos: Especie tropical de aguas intermedias (50-100 m) (Kennett \& Srinivasan 1983). Se registra por primera vez esta especie para la zona de Coquimbo $\left(30^{\circ} \mathrm{S} ; 73^{\circ} \mathrm{W}\right)$ durante condición El Niño 1997-98.

\section{Globorotalia truncatulinoides (d'Orbigny 1839)} Figura 7 (Figs. 7.1-7.4)

Rotalina truncatulinoides d'Orbigny 1839 In BarkerWebb \& Berthelot, Hist. Nat. Iles Canaries "Foraminiferes" 2(2): 132, lám. 2, figs. 25-27 (fide Jenkins 1971)

Globorotalia truncatulinoides (d'Orbigny). Cushman \& Wickenden 1929: 14, lám. 6, fig. 3; Parker 1962: 239, lám. 6, fig. 7; Kustanowich 1963: 561, lám. 2, figs. 27-29; Jenkins 1964: 26, text-fig. 1 (list); Bandy \& Rodolfo 1964: 823; Boltovskoy 1976: 230; Boltovskoy 1981: 320, 341, 350, fig. 162 (20) y 168 (42a-c, 43a-c); Zapata \& Castillo 1986: 57, figs. 23-25; Hemleben et al. 1989: 25, 26, fig. 2.6 d-f; Zapata \& Cea 2002: 65, 71, 72, lám. 4, fig. 6; lám. 5, figs. 1-2.

Globorotalia (Globorotalia) truncatulinoides (d’Orbigny). Jenkins 1971: 98, lám.6, figs. 158-160. Globorotalia (Truncorotalia) truncatulinoides (d'Orbigny). Kennett \& Srinivasan 1983: 148, lám. 34, fig. 2, lám. 35, figs. 4-6.

Material estudiado: Trampa CH10-2, muestras 1, 9, 14, 17-19; trampa CH11-2, muestras 2, 7, 8, 11; total ejemplares: 17 .

Museo: UCCC No 26950, 1 ejemplar de CH11-2 №2 $>212 \mu \mathrm{m}$.

CARACTERÍsTICA PRINCIPAL: Conchilla trocoespiral plano-cónica con enrollamiento dextral o levógiro, superficie lisa parcialmente pustulosa con poros pequeños, carece de espinas, margen periférico con quilla limbada, largo máximo $0.9 \mathrm{~mm}$. Cámaras angulosas cónicas, última vuelta con 6 cámaras en juveniles y 5 a 5 1/2en adultos. Abertura extraumbilical con labio (Boltovskoy 1981). 
Otros ASPECTOS: Esta especie también ha sido citada pero no descrita ni figurada, Boltovskoy \& Watanabe (1975) y por Marchant et al. (1998).

G. truncatulinoides vive a grandes profundidades. Se reproduce en aguas superficiales durante primavera y migra posteriormente hasta los $1000 \mathrm{~m}$ de profundidad o más (Hemleben et al. 1985 In Kemle-von Mücke \& Hemleben 1999). Esta especie tiende a aumentar la proporción de ejemplares levógiros con la disminución de las temperaturas (Boltovskoy 1981). El límite de tolerancia de temperatura $\left(\mathrm{TSM}^{\circ} \mathrm{C}\right)$ para esta especie está entre los 2.9 y $27^{\circ} \mathrm{C}$ (Boltovskoy \& Wright 1976).

\section{Globorotalia tumida (Brady 1877)}

Pulvinulina menardii, var.tumida Brady 1877: 294; Brady 1879: 80; Banner \& Blow 1960b: 26, lám. 5, fig. 1 (lectotype); Boltovskoy 1976: 230.

Pulvinulina tumida Brady 1884: 692, lám. 103, figs. 4-6.

Globorotalia tumida (Brady). Cushman 1927: 91, lám. 19, fig. 12; Parker 1962: 239, lám. 6, figs. 810; Kustanowich 1963: 562, 1. 1. No 10-12.

Globorotalia (Globorotalia) tumida (Brady). Jenkins 1971: 99, lám.7, fig. 164-166.

Globorotalia tumida (Brady). Boltovskoy 1976: 230; 1981: 320, 342, figs. 162 (14) y 168 c).

Globorotalia (Globorotalia) tumida tumida (Brady). Kennett \& Srinivasan 1983: 158, lám. 36, figs. 1, 2; lám. 38, figs. 1-3.

Globorotalia tumida (Brady). Hemleben et al. 1989: 27, fig. $2.6 \mathrm{~g}-\mathrm{i}$.

Material estudiado: Trampa CH10-2, muestras 14, 15; total ejemplares: 2.

CARACTERÍstica PRINCIPAL: Conchilla trocoespiral aplanada de paredes gruesas, con enrollamiento levógiro, superficie lisa en juveniles y groseramente cristalina en adultos; con poros muy pequeños, carece de espinas, margen periférico con quilla, largo máximo $1.4 \mathrm{~mm}$. Cámaras angulosas romboidales, última vuelta con 5-6 cámaras. Abertura extraumbilical con labio.

Otros aspectos: Especie de aguas cálidas intermedias, más abundante en el océano Pacífico que en el Atlántico (Boltovskoy 1981). Se le encuentra por debajo de los de 50 metros y en varias instancias bien debajo de 500 metros; posee un amplio rango batimétrico, encontrando sus fases tempranas en la zona eufótica y sus fases tardías en profundidades meso- o batipelágicas (Bé \& Tolderlund 1971).

Se registra por primera vez esta especie para la zona de Coquimbo $\left(30^{\circ} \mathrm{S} ; 73^{\circ} \mathrm{W}\right)$ durante condición El Niño 1997-98.

Neogloboquadrina dutertrei (d'Orbigny 1839) Figura 8 (Figs. 8.1-8.4)

Globigerina dutertrei d'Orbigny 1839, de la Sagra, Hist. Phys. Pol. Nat. Cuba, "Foraminiferes", 8: 84, lám. 4, figs. 19-21 (fide Jenkins, 1971); Heron-Allen \& Earland 1932: 177; Banner \& Blow 1960b: 11, lám. 2, fig. 1 (lectotipo); Boltovskoy \& Theyer 1970: 367, lám. 6, fig. 1 .

Globigerina dubia Egger. Brady 1884: 595, lám 79, fig. 17.

Globorotalia humerosa Takayanagi \& Saito 1962: 78, lám. 28, fig. 1-2b.

Globorotalia apertura Pezzani 1963: 571, lám. 30, fig. 1a-c; lám. 32, figs. 9a-c; 10.

Globorotalia $c f$. dutertrei (d'Orbigny). Jenkins 1964: 25, text-fig. 1 (list).

Globigerina eggeri Akers \& Dorman 1964: 15, lám. 12, figs. 6-8.

Globorotalia (turborotalia) dutertrei (d'Orbigny). Jenkins 1971: 114, lám. 11, figs. 273-275.

Globoquadrina dutertrei (d'Orbigny). Boltovskoy 1976: 229; Boltovskoy 1981: 320, 340, 349, figs. 162 (5) y 168 (24a-c); Zapata \& Castillo 1986: 56, figs. 14-15.

Neogloboquadrina dutertrei (d'Orbigny). Kennett \& Srinivasan 1983: 198, lám. 48, figs. 7-9; Hemleben et al. 1989: 22, fig. 2.4 e, f; Zapata \& Cea 2002: 66, lám. 5, figs. 3-4.

Material estudiado: Trampa CH10-2, muestras 114, 16-20; CH11-2, muestras 2-18, 20; total ejemplares: 866 .

Museo: UCCC No 26951, 10 ejemplares de CH11$2 \mathrm{~N}^{\mathrm{o}} 10>212 \mu \mathrm{m}$.

CARACTERÍstica PRINCIPAL: Conchilla trocoespiral, 
con enrollamiento dextral o levógiro, paredes gruesas, superficie groseramente escrobiculada con poros medianos, carece de espinas, margen periférico redondeado, largo máximo $0.7 \mathrm{~mm}$. Cámaras subglobosas, última vuelta con 5-6 cámaras en juveniles y 4-6 en adultos. Abertura umbilical grande, abierta, con dientes umbilicales.

Otros Aspectos: Marchant et al. (1998) la cita pero no la figura ni describe.

$N$. dutertrei se distribuye en mayores densidades en aguas tropicales y en menor en aguas transicionales (Boltovskoy 1981). El límite de tolerancia de temperatura $\left(\mathrm{TSM}^{\circ} \mathrm{C}\right)$ para esta especie está entre los 9 y $30^{\circ} \mathrm{C}$ (Boltovskoy \& Wright 1976). En cuanto a la relación entre abundancia y temperatura, esta especie responde a cambios de temperatura superficial, al contrario de G. calida (Boltovskoy 1981).

Está presente en sistemas de corrientes activos, a lo largo de márgenes continentales y en zonas de surgencia (regiones de alta productividad primaria y profundidad máxima de clorofila). Prefiere la zona fótica estratificada, dentro de la termoclina y posee una pronunciada abundancia entre los 25 y $50 \mathrm{~m}$ sobre la termoclina (Bé \& Tolderlund 1971, Fairbanks et al. 1980, Fairbanks et al. 1982, Marchant 1997). Batimétricamente se le considera de aguas intermedias (50-100 m) (Boltovskoy 1981). Para el área de Coquimbo, N. dutertrei es indicadora de condición El Niño debido al aumento de su abundancia con el alza de la temperatura (Marchant et al. 1998). Para condiciones normales, y fines de 1995-96 y entre abril-junio 1996 tendió a casi desaparecer (Giglio 2001).

Neogloboquadrina pachyderma (Ehrenberg 1861)*

Aristerospira pachyderma Ehrenberg 1861: 303; 1873: 386, lám. 1, fig. 4; Boltovskoy 1976: 229.

Globigerina bulloides var. borealis Brady 1881, Ann. Mag. Nat. Hist., ser. 5, 8(48): 412 (fide Jenkins, 1971, et seq.); Brady 1884: 600, lám. 114, fig. 1920; Banner \& Blow 1960b: 4, lám.3, fig. 4a-c (lectotype).

Globigerina pachyderma(Ehrenberg). Heron-Allen \& Earland 1932: 401, lám 13, figs. 9-13; Bandy 1960: 671, text-fig. 1; Takayanagi \& Saito 1962: 89, lám. 26, fig. 4a-c; Parker 1962: 224, lám. 1, figs. 2635, lám. 2, fig. 1-6; Pezzani 1963: 585, lám.30, fig. 6a-b; lám. 31, fig.12a-b; Bandy \& Rodolfo 1964: 826; Boltovskoy \& Theyer 1970: 369. Lám. 6, figs. 8-9, 12; Boltovskoy 1976: 229; Zapata \& Castillo 1986: 54, figs. 7-8.

Globorotalia (Turborotalia) pachyderma (Ehrenberg). Jenkins 1971: 128, lám. 12, figs. 345347.

Globoquadrina pachyderma (Ehrenberg). Boltovskoy 1981: 340, fig. 168 (21a-c, 22a-c y 23ac).

Neogloboquadrina pachyderma (Ehrenberg). Kennett \& Srinivasan 1983: 192, lám. 47, figs. 2, 68; Hemleben et al. 1989: 22, fig. 2.4 g-l; Zapata \& Cea 2002: 66, 72, lám. 5, figs. 3-4.

*Las variedades dextral (dex.) y levógira (lev.) de Neogloboquadrina pachyderma se consideran especies distintas, en vista de sus hábitat diferentes (Boltovskoy 1976, Marchant et al. 1998).

\section{Neogloboquadrina incompta (Cifelli 1961)* Figura 9 (Figs. 9.1-9.4)}

Globigerina pachyderma (Ehrenberg 1861), f. dextralis Boltovskoy 1976: 211, 213.

Neogloboquadrina incompta (Cifelli 1961). Boltovskoy 1981: 60; Kemle-von Mücke \& Hemleben 1999: 57.

*Forma dextral de $N$. pachyderma $(=N$. pachyderma (dex.))

Material estudiado: Trampa CH10-2, muestras 120; trampa CH11-2, muestras 2-20; total ejemplares: 12.872 .

Museo: UCCC No 26952, 10 ejemplares de CH10-2 $\mathrm{N}^{\mathrm{o}} 19>212 \mu \mathrm{m}$.

CARACTERÍSTICA PRINCIPAL: Conchilla trocoespiral, con enrollamiento dextral, superficie rugosa con poros pequeños, carece de espinas, margen periférico redondeado, largo máximo $0.5 \mathrm{~mm}$. Cámaras subglobosas, última vuelta con 41/2-5 cámaras. Abertura umbilical extraumbilical angosta con labio (Boltovskoy 1981).

Otros ASPECtos: Zapata \& Cea (2002) citan esta especie como N. pachyderma en su variedaddextralis, 
describiéndola y figurándola; Marchantet al.(1998), la citan como $N$. pachyderma (dex.) diferenciándola de N. pachyderma ( $\sin$.) por su hábitat, las nombra pero no las describe ni figura. La forma dextral de $N$. pachyderma habita comúnmente en zonas subantárticas y al norte de los $33^{\circ} \mathrm{S}$ en aguas templadas frías (Boltovskoy 1981) y prefiere hábitat más cálidos que la forma levógira (Ericson 1959). Es común en aguas que poseen temperaturas mayores a $8^{\circ} \mathrm{C}$ (Reynolds \& Thunell 1986). El límite de tolerancia de temperatura $\left(\mathrm{TSM}^{\circ} \mathrm{C}\right)$ para esta especie está entre los 0 y $24^{\circ} \mathrm{C}$ (Boltovskoy \& Wright 1976).

Neogloboquadrina pachyderma (Ehrenberg 1861)* Figura 10 (Figs. 10.1-10.4)

Globigerina pachyderma (Ehrenberg 1861), f. sinistralis Boltovskoy 1976: 211, 213.

Neogloboquadrina pachyderma (Ehrenberg 1861). Kemle-von Mücke \& Hemleben 1999: 57, figs. $6.27 \mathrm{a}-\mathrm{d}$

*Forma levógira de N. pachyderma $(=N$. pachyderma (lev.)).

Material estudiado: Trampa CH10-2, muestras 120; trampa CH11-2, muestras 2-15, 16-20; total ejemplares: 2.344 .

Museo: UCCC N $\mathrm{N}^{\circ}$ 26953, 11 ejemplares de CH11-2 $\mathrm{N}^{\mathrm{o}} 12>212 \mu \mathrm{m}$.

CARACTERÍSTICA PRINCIPAL: Conchilla trocoespiral, con enrollamiento levógiro, superficie rugosa con poros pequeños, carece de espinas, margen periférico redondeado. Cámaras subglobosas, última vuelta con 4 cámaras. Abertura umbilical extraumbilical angosta con labio. De talla menor que la variedad dextral.

Otros Aspectos: La forma levógira de N. pachyderma se distribuye al sur de los $33^{\circ} \mathrm{S}$, siendo predominante en aguas del Frente Polar. Se encuentra por debajo de la termoclina (50-100 $\mathrm{m}$ de profundidad), en aguas con temperaturas menores a los $8^{\circ} \mathrm{C}$ (Boltovskoy 1981, Bé \& Tolderlund 1971, Sautter \& Thunell 1991). El límite de tolerancia de temperatura $\left(\mathrm{TSM}^{\circ} \mathrm{C}\right)$ para esta especie está entre los $-1,4$ y $24^{\circ} \mathrm{C}$ (Boltovskoy \& Wright 1976). Esta especie responde a los cambios de temperatura en aguas más profundas que a los cambios superficiales al igual que G. calida (Giglio 2001). Su máxima abundancia está en la zona de mayor concentración de clorofila. Esta especie es indicadora de intensidad de surgencia para la zona de Coquimbo (Marchant 1997, Marchant et al. 1998).

Pulleniatina obliquiloculata (Parker \& Jones 1865) Figura 11 (Figs. 11.1-11.5)

Pullenia obliquiloculata Parker \& Jones 1862: 183. Pullenia sphaeroides var. obliquiloculata Parker \& Jones 1865: 365 y 368, lám. 19, figs. 4a-b; Boltovskoy 1976: 230.

Pulleniatina obliquiloculata (Parker \& Jones 1865). Boltovskoy 1976: 230; Boltovskoy 1981: 320, 341, 348, figs. 162 (16) y 168 (18a-c); Kennett \& Srinivasan 1983: 202, lám. 49, fig. 2; lám. 50, figs. 6-9; Hemleben et al.1989: 28, fig. 2.7 c, d.

Material estudiado: Trampa CH10-2, muestra 13; total ejemplares: 4 .

CARACTERÍstiCA PRINCIPAL: Conchilla trocoespiral transformándose en estreptoespiral, con enrollamiento dextral, superficie escrobiculada en juveniles y lisa en adultos, brillante, con poros pequeños, carece de espinas, con margen periférico redondeado, largo máximo $0,8 \mathrm{~mm}$. Cámaras hemiesféricas, las últimas más superpuestas; última vuelta con $4-5$ cámaras y 31/2-41/2 en adultos. Abertura umbilical extraumbilical con reborde.

Otros AsPectos: Especie de aguas cálidas (zona tropical) de temperatura entre 24 y $30^{\circ} \mathrm{C}$ (Bé \& Tolderlund 1971). Batimétricamente, se le encuentra en aguas intermedias (50-100 m) (Boltovskoy 1981).

Tenuitella iota (Parker 1962)

Figura 12 (Figs. 12.1-12.5)

Globigerinita iota Parker 1962: 250, lám. 10, figs. 26-30.

Globigerina atlantisae Cifelli \& Smith 1970: 52.

Globigerinita iota Parker 1962. Boltovskoy 1981: 342, 349, fig. 168 (32a-b).

Tenuitella iota (Parker, 1962). Hemleben et al. 1989: 30, 31, fig. 2.7 q. 
Material estudiado: Trampa CH10-2, muestras 1420; trampa CH11-2, muestras 2, 4; total ejemplares: 35 .

Museo: UCCC No 26947, 1 ejemplar de CH10-2 No $14>212 \mu \mathrm{m}$.

CARACTERÍstica PRINCIPAL: Conchilla trocoespiral aplanada, con enrollamiento dextral o levógiro, superficie lisa o finamente híspida, con poros muy pequeños, carece de espinas, margen periférico redondeado, largo máximo $0.22 \mathrm{~mm}$. Cámaras subglobosas, última vuelta con 5 cámaras en juveniles y 4-5 en adultos. Abertura umbilical extraumbilical con labio delgado, con bulla aplanada con forma de mano. A veces con abertura secundaria infralaminar (Boltovskoy 1981).

Otros ASPeCtos: Esta especie prefiere aguas frías. $\mathrm{Su}$ flujo siempre es escaso (Kemle-von Mücke \& Hemleben 1999).

\section{Globigerinita glutinata (Egger 1893) \\ Figura 13 (Figs. 13.1-13.4)}

Globigerina glutinata Egger 1893: 371, lám. 13, figs. 19-21.

Globigerinita glutinata (Egger 1893). Boltovskoy, 1976: 229; Boltovskoy 1981: 342, 349, fig. 168 (30ac); Kennett \& Srinivasan 1983: 224, lám. 56, figs. 1, 3-5; Hemleben et al. 1989: 28, fig. 2.7 e-h; Zapata \& Cea 2002: 63, 68, lám. 1, figs. 1-2

Material estudiado: Trampa CH10-2, muestras 1-10, 12-20; trampa CH11-2, muestras 2-15, 17-20; total ejemplares: 822 .

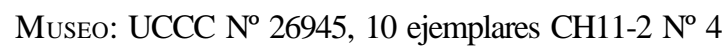
$>212 \mu \mathrm{m}$.

CARACTERÍSTICA PRINCIPAL: Conchilla trocoespiral, con enrollamiento dextral o levógiro, superficie lisa, finamente híspida, con poros muy pequeños, carece de espinas, margen periférico redondeado, longitud máxima $0.5 \mathrm{~mm}$. Cámaras globosas. Última vuelta con 5 cámaras en juveniles y 4 en adultos. Abertura umbilical, frecuentemente tapada con una bulla (infralaminar), con labio grande. Abertura secundaria infralaminar. La bulla se desarrolla en estado terminal (Boltovskoy 1981).
Otros Aspectos: Es considerada cosmopolita, se le encuentra desde el Ecuador hasta latitudes altas. Batimétricamente se establece de aguas intermedias (50-100 m). Aparentemente puede tolerar un amplio rango de temperatura y salinidad (Boltovskoy 1981). Boltovskoy \& Wright (1976), indican que el límite de tolerancia de temperatura $\left(\mathrm{TSM}^{\circ} \mathrm{C}\right)$ para esta especie está entre los $0.3 \mathrm{y}$ $30^{\circ} \mathrm{C}$. La máxima de abundancia se encuentra entre los $24^{\circ}$ y $27^{\circ} \mathrm{C}$ (Bé \& Tolderlund 1971).

\section{Globigerinita uvula (Ehrenberg 1861) \\ Figura 14 (Figs. 14.1-14.5)}

Pilodexia uvula Ehrenberg 1861: 276, 277, 308; Ehrenberg 1873: 1872, lám. 2, figs. 24, 25.

Globigerinita uvula (Ehrenberg 1861). Boltovskoy 1976: 229; Boltovskoy 1981: 320 , 342, 349, figs. 162 (13) y 168 (31a-c); Kennett \& Srinivasan 1983: 224, lám. 56, figs. 1, 3-5; Hemleben et al. 1989: 30, fig. 2.7 n-p.

Material Estudiado: Trampa CH10-2, muestras 2, 4-6, 8, 11, 13, 14, 16-18, 20; trampa CH11-2, muestras 2-8, 11, 12, 14, 19; total ejemplares: 203.

Museo: UCCC No 26946, 3 ejemplares de CH11$2 \mathrm{~N}^{\circ} 5>212 \mu \mathrm{m}$.

CARACTERÍSTICA PRINCIPAL: Conchilla muy pequeña $(170 \mu \mathrm{m})$ con forma trocoespiral alta, racimosa, con enrollamiento dextral o levógiro, superficie lisa, en partes finamente híspida, con poros muy pequeños, carece de espinas, margen periférico redondeado, longitud máxima $0.2 \mathrm{~mm}$. Cámaras globosas, última vuelta con 5 cámaras en juveniles y 4 en adultos. Abertura umbilical a veces infralaminar, con labio pequeño o sin él. A veces con abertura secundaria infralaminar (Boltovskoy 1981). Se encontraron algunos especímenes con un diente en la abertura.

Otros ASPECtos: Especie típica de aguas antárticas y subantárticas, también presente en la Zona de Transición, pero en menor abundancia. El límite de tolerancia de temperatura $\left(\mathrm{TSM}^{\circ} \mathrm{C}\right)$ para esta especie está entre los -0.58 y $25^{\circ} \mathrm{C}$ y el rango de salinidad entre 30.5 y 31 psu (Boltovskoy \& Wright 1976, Boltovskoy 1981). 
Esta especie sólo se había registrado en la Zona de Transición y área de Coquimbo en condición normal (Boltovskoy 1976, Marchant et al. 1998). Se registra por primera vez para la zona de Coquimbo $\left(30^{\circ} \mathrm{S}, 73^{\circ} \mathrm{W}\right)$, durante condición El Niño 1997-98, principalmente en el período de mayor surgencia.

Globorotaloides hexagonus (Natland 1938) Figura 15 (Figs. 15.1-15.6)

Globigerina hexagona Natland 1938: 149, lám. 7, fig. 1.

Globoquadrina hexagona (Natland). Boltovskoy 1976: 230; Boltovskoy 1981: 340, 349, fig. 168 (25a-c).

Globigerinoides hexagona(Natland). Kennett \& Srinivasan 1983: 216, lám. 54, figs. 1, 3-5.

Globorotaloides hexagonus (Natland). Hemleben et al. 1989: 27, fig. 2.6 n-p.

Material estudiado: Trampa CH10-2, muestras 1-9, 11-20; trampa CH11-2, muestras 2-14, 1619; total ejemplares: 235.

CARACTERÍsTICA PRINCIPAL: Conchilla trocoespiral muy aplanada, con enrollamiento dextral o levógiro, superficie híspida rugosa (escrobiculadas), con poros medianos, carece de espinas, margen periférico redondeado, largo máximo $0.6 \mathrm{~mm}$. Cámaras subglobosas, última vuelta con 5 cámaras. Abertura umbilical con labio transformándose a extraumbilical (Boltovskoy 1981).

Otros aspectos: Se le encuentra viviendo en los océanos Pacífico e Indico pero no en el Atlántico (se cree que desapareció de éste durante la última época interglacial) (Boltovskoy 1981). Especie de aguas cálidas. El límite de tolerancia de temperatura $\left(\mathrm{TSM}^{\circ} \mathrm{C}\right)$ para esta especie está entre los 25 y $30{ }^{\circ} \mathrm{C}$ (Boltovskoy \& Wright 1976). De aguas profundas. Vive en la zona fótica cuando joven y desciende a profundidades mayores de 100 m al madurar (Boltovskoy 1981).

Especie raramente abundante en Coquimbo durante El Niño 1991-92 (Marchant et al. 1998), 1997-98 y Condición Normal 1993-94 (Marchant et al. 1998).

\section{Globigerina bulloides d'Orbigny 1826 \\ Figura 16 (Figs. 16.1-16.4)}

Globigerina bulloides d'Orbigny 1826 Tableau Methodique de la classe des Cephalopodes, Anns. Sci. Nat.: 277 (sin figura) list $\mathrm{N}^{\mathrm{o}} 1$ (fide Ellis \& Messina 1940, et seq.) In Jenkins 1971; d'Orbigny 1839: 460; Brady 1884: 593, lám. 79, figs. 3, 7; Banner \& Blow 1960b: 3, lám. 1, figs. 1, 4 (lectotipo); Hornibrook 1961: 146, lám. 21, figs. 430-431, 434; Bandy \& Rodolfo 1964: 826; Boltovskoy \& Theyer 1970: 367, lám. 6, fig. 3; Zapata \& Varela 1975: 17, lám. 2, fig. 3; Boltovskoy 1981: 320, 339, 343, figs. 162 (17) y 168 (1a-c); Zapata \& Castillo 1986: 53, figs. 2-3; Hemleben et al. 1989: 10, fig. 2.1a-c; Zapata \& Cea 2002: 63, 68, lám. 1, figs. 3-4.

Globigerina praebulloides Blow 1959: 180-1, lám. 8, fig. 47a-c; lám. 9, fig. 48; Jenkins 1960: 352, lám. 2, fig. 1a-c.

Globigerina parabulloides Blow 1959: 179, lám. 10, fig. $476 \mathrm{a}-\mathrm{c}$.

Globigerina (Globigerina) bulloides d'Orbigny 1826 In Jenkins 1971: 141, lám. 14, figs. 408-410; Kennett \& Srinivasan 1983: 36, lám. 6, figs. 4-6

Material estudiado: Trampa CH10-2, muestras 1-20; trampa CH11-2, muestras 2-20; total ejemplares: 7.459 .

Museo: UCCC No 26934, 10 ejemplares CH10-2 No $17>212 \mu \mathrm{m}$.

CARACTERÍsticas PRINCIPAles: Conchilla trocoespiral baja, de superficie híspida, con poros pequeños, con espinas delgadas de corte circular, margen periférico redondeado, largo máximo $0.8 \mathrm{~mm}$, el enrollamiento puede ser dextral o levógiro. Cámaras esféricas a subesféricas incrementando regularmente en tamaño, última vuelta con 5 cámaras en juveniles y 4 en adultos. Abertura umbilical grande, sin labio, ubicada en la base abertural de la última cámara abriéndose en el atrio umbilical (Boltovskoy 1981).

Otros ASPECtos: El proloculus en G. bulloides presenta características biológicas que sitúa a esta especie en el límite entre las especies espinosas y no espinosas (Hemleben et al. 1989). Se le encuentra en gran abundancia en regiones polares y de transición; temperatura óptima: $11-16^{\circ} \mathrm{C}$ (Fairbanks et al. 1982). El límite de tolerancia de temperatura $\left(\mathrm{TSM}^{\circ} \mathrm{C}\right)$ para 
Гigura 3

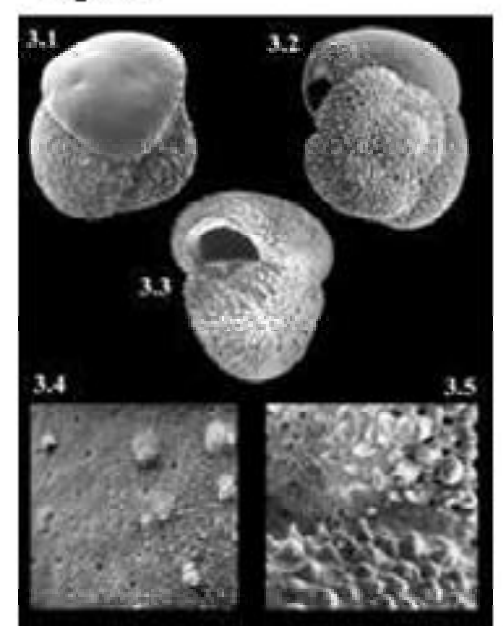

Tigura 6

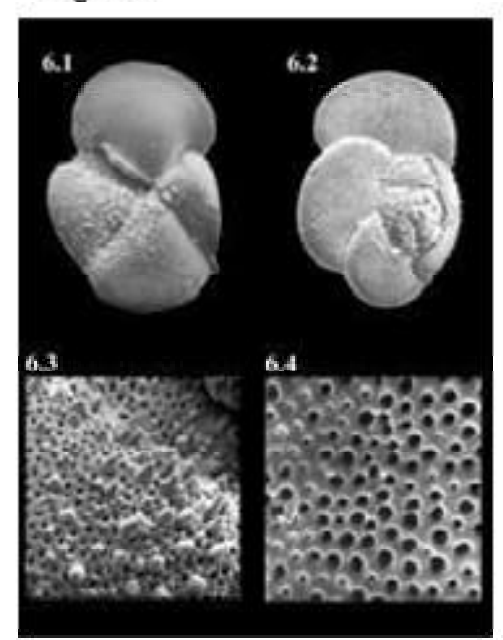

Гigura?

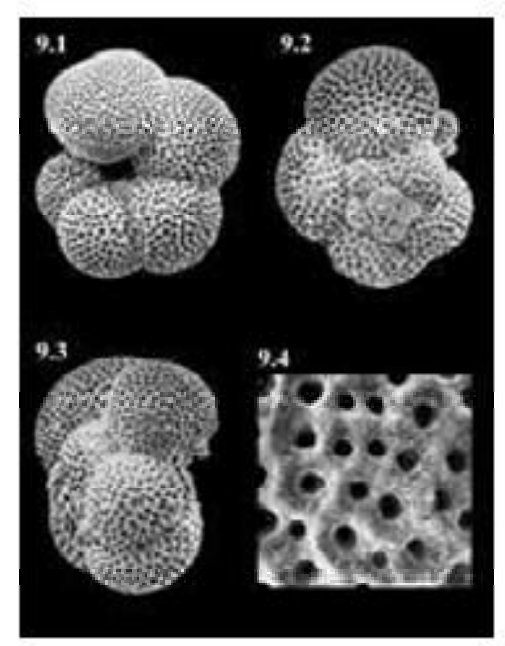

Гigura 4

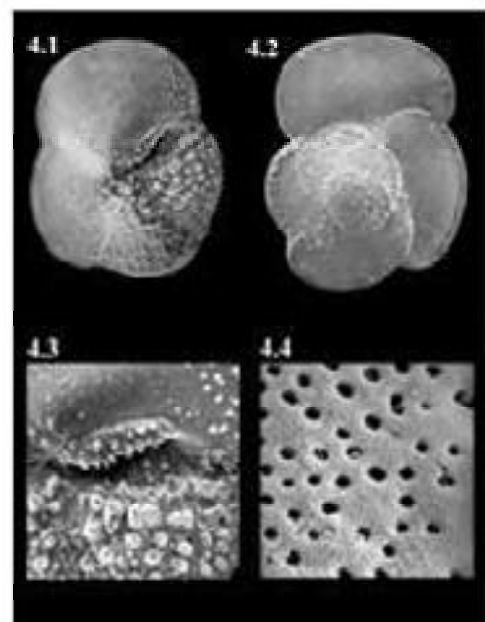

Figura ?

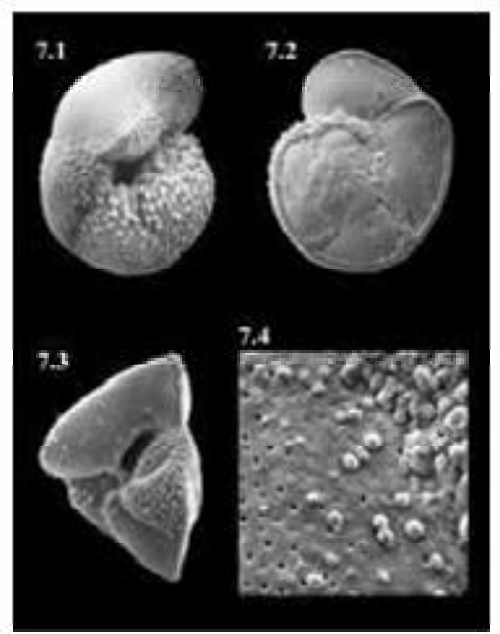

Figura 10

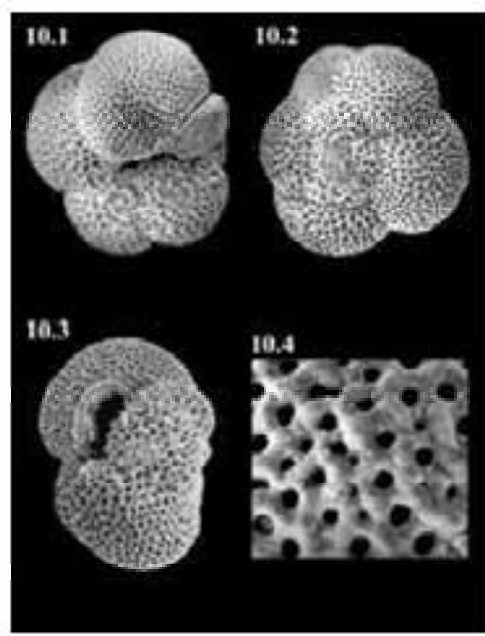

Гignum 5

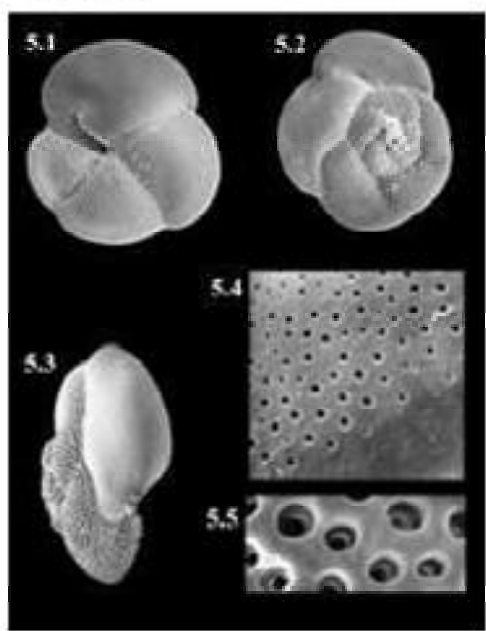

Fizura 8

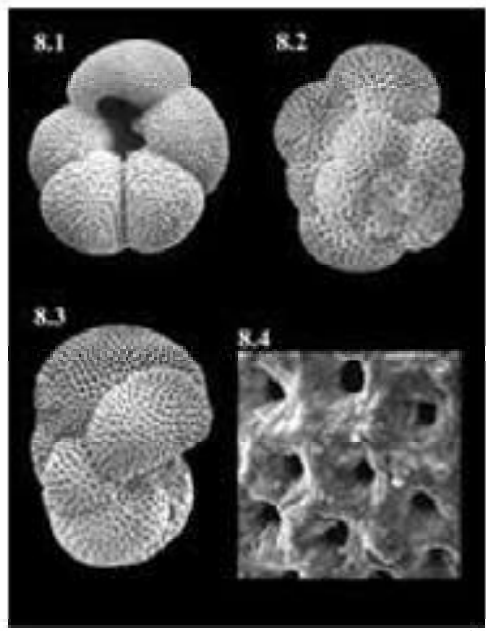

[izzura II

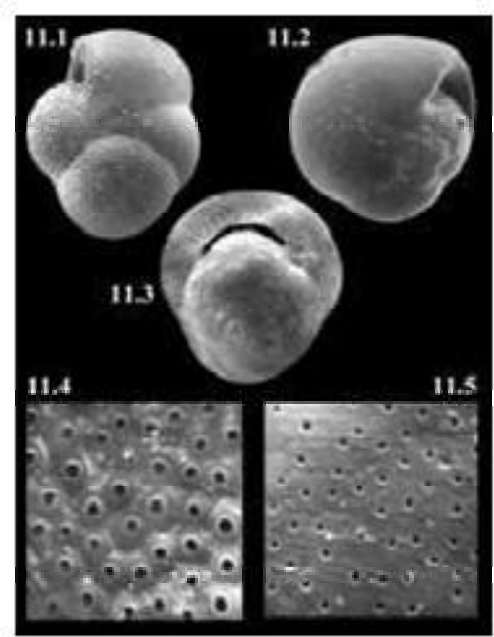


esta especie está entre los -0.7 y $27^{\circ} \mathrm{C}$ y un rango de salinidad entre 30.5 y 31 psu (Boltovskoy \& Wright 1976). Esta especie tiende a aumentar la proporción de ejemplares levógiros con la disminución de las temperaturas (Boltovskoy 1981). Vive en la capa de mezcla (Steens et al. 1992). En la columna de agua se le encuentra sobre los 400 metros, pero principalmente sobre la termoclina, entre 0-50 m (Fairbankset al.1982, Hemleben et al. 1989). Además, esta especie es indicadora de aguas de surgencia (Cullen \& Prell 1984, Marchant et al.1998). En aguas chilenas, es dominante en zonas de surgencias y mar abierto (Marchantetal. 1998).

Para la zona de Coquimbo en condición El Niño, la abundancia relativa de $G$. bulloides disminuye desde un 60-70 \% a 10-30\% (Marchant 1997, Coloma et al. 2002).

\section{Globigerinella calida (Parker 1962)}

Figura 17 (Figs. 17.1-17.5)

Globigerina calida Parker 1962: 221, lám. 1, figs. 913, 15; Zapata \& Castillo 1986: 54, figs. 4-6. Globigerinella calida (Parker). Boltovskoy 1981:320, 340, 349, figs. 162 (1) y 168 (28a-c); Kennett \& Srinivasan 1983: 240, lám. 60, figs. 7-9; Hemleben $e t$ al. 1989: 18, fig. 2.3 e, f; Zapata \& Cea 2002: 63, 68, lám. 1, figs. 5-6.

Material estudiado: Trampa CH10-2, muestras 1-20; trampa CH11-2, muestras 2-20; total ejemplares: 1.787.

MUSEO: UCCC No 26936, 10 ejemplares CH10-2 $\mathrm{N}^{\mathrm{o}} 17>212 \mu \mathrm{m}$.

Figuras 3-11. Fig. 3. Globorotalia inflata (d'Orbigny 1839); 1) Ventral, 195x (Ex: CH10-2 No14); 2) Dorsal, 160x (Ex: CH8-2 No18); 3) Lateral, 160x (Ex: CH8-2 Nº18); 4) Pared última cámara, 1600x (Ex: CH8-2 No 18); 5) Pared, cercano a la abertura, 800x (Ex: CH5-2 №11). Fig. 4. Globorotalia menardii (d'Orbigny 1826); 1) Ventral, 160x (Ex: CH8-2 No16); 2) Dorsal, 90x (Ex: CH10-2 No14); 3) Pared del área de la abertura, 400x (Ex: CH8-2 No 16); 4) Detalle pared dorsal penúltima cámara, 1600x (Ex: CH8-2 №18). Fig. 5: Globorotalia scitula (Brady 1882); 5.1. Ventral, 200x (Ex: CH5-2 No8); 2) Dorsal, 220x (Ex: CH5-2 N²); 3) Lateral, 280x (Ex: CH5-2 No8); 4. Pared ventral, 1120x (Ex: CH5-2 No8); 5) Detalle pared dorsal, 2200x (Ex: CH5-2 №2). Fig. 6. Globorotalia theyeri Fleisher 1974; 1) Ventral, 120x (Ex: CH10-2 No18); 2) Dorsal, 165x (Ex: CH10-2 No18); 3) Pared del área de la abertura, 600x (Ex: CH10-2 No18); 4) Detalle pared dorsal, 1200x (Ex: CH10-2 N¹8). Fig. 7. Globorotalia truncatulinoides (d'Orbigny 1839); 1) Ventral, 170x (Ex: CH10-2 Nº); 2. Dorsal, 170x (Ex: CH10-2 No1); 3. Lateral, 200x (Ex: CH10-2 No19); 4) Pared, 960x (Ex: CH8-2 No18). Fig. 8. Neogloboquadrina dutertrei (d'Orbigny 1839); 1) Vista ventral, 120x (Ex: CH10-2 No2); 2) Dorsal, 136x (Ex: CH5-2 N7); 3) Lateral, 136x (Ex: CH5-2 No7); 4) Pared, 1360x (Ex: CH5-2 No7). Fig. 9. Neogloboquadrina incompta (Cifelli 1961); 1) Ventral, 200x (Ex: CH5-2 No1); 2) Dorsal, 260x (Ex: CH5-2 $\mathrm{N}^{\circ} 7$ ); 3) Lateral, 260x (Ex: CH5-2 ํo7); 4) Pared, 1600x (Ex: CH5-2 ํo7). Fig. 10. Neogloboquadrina pachyderma (Ehrenberg 1861); 1) Vista ventral, 260x (Ex: CH8-2 No16); 2) Dorsal, 240x (Ex: CH8-2 No 16); 3) Lateral, 280x (Ex: CH8-2 N¹6); 4) Pared, 1200x (Ex: CH8-2 No16). Fig. 11. Pulleniatina obliquiloculata Parker \& Jones 1865; 1) Ventral, 128x (Ex: CH10-2 N¹3); 2) Dorsal, 130x (Ex: CH10-2 Nº13); 3) Lateral, 120x (Ex: CH10-2 No13); 4) Pared última cámara de la figura 1, 1120x (Ex: CH10-2 N¹3); 5) Pared última cámara de la figura 1, 1120x (Ex: CH10-2 $\left.\mathrm{N}^{\circ} 13\right)$.

FiguRES 3-11. Fig. 3. Globorotalia inflata (d'Orbigny 1839); 1) Ventral, 195x (Ex: CH10-2 No14); 2) Dorsal, 160x (Ex: CH8-2 N¹8); 3) Lateral, 160x (Ex: CH8-2 No18); 4) Wall last camer, 1600x (Ex: CH8-2 No18); 5) Wall, near to the opening, 800x (Ex: CH5-2 №11). Fig. 4. Globorotalia menardii (d'Orbigny 1826); 1) Ventral 160x (Ex: CH8-2 $\left.\mathrm{N}^{\circ} 16\right)$; 2. Dorsal, 90x (Ex: CH10-2 N¹4); 3) Wall, near to the opening, 400x (Ex: CH8-2 $\left.\mathrm{N}^{\circ} 16\right)$; 4) Detail dorsal wall penultimate camera, 1600x (Ex: CH8-2 No18). Fig. 5. Globorotalia scitula (Brady 1882); 1) Ventral, 200x (Ex: CH5$2 \mathrm{~N}^{\circ} 8$ ); 2) Dorsal, 220x (Ex: CH5-2 No2); 3) Lateral, 280x (Ex: CH5-2 No8); 4. Wall ventral, 1120x (Ex: CH5-2 No8); 5) Detail dorsal wall, 2200x (Ex: CH5-2 №2). Fig. 6. Globorotalia theyeri Fleisher 1974; 1) Ventral, 120x (Ex: CH10$2 \mathrm{~N}^{\circ} 18$ ); 2) Dorsal view, 165x (Ex: CH10-2 No18); 3) Wall, near to the opening, 600x (Ex: CH10-2 No 18); 4) Detail dorsal wall, 1200x (Ex: CH10-2 No18). Fig. 7. Globorotalia truncatulinoides (d'Orbigny 1839); 1) Ventral view, 170x (Ex: CH10-2 No1); 2) Dorsal, 170x (Ex: CH10-2 No1); 3) Lateral, 200x (Ex: CH10-2 No19); 4) Wall, 960x (Ex: CH8-2 No18). Fig. 8. Neogloboquadrina dutertrei (d'Orbigny 1839); 1) Ventral, 120x (Ex: CH10-2 No2); 2) Dorsal, 136x (Ex: CH5-2 No7); 3) Lateral, 136x (Ex: CH5-2 No7); 4. Wall, 1360x (Ex: CH5-2 No7). Fig. 9. Neogloboquadrina incompta (Cifelli 1961); 1) Ventral, 200x (Ex: CH5-2 No1); 2) Dorsal, 260x (Ex: CH5-2 №7); 3) Lateral, 260x (Ex: CH5-2 N7); 4) Wall, 1600x (Ex: CH5-2 №7). Fig. 10. Neogloboquadrina pachyderma (Ehrenberg 1861); 1) Ventral, 260x (Ex: CH8-2 No16); 2) Dorsal, 240x (Ex: CH8-2 N¹6); 3) Lateral, 280x (Ex: CH8-2 N¹6); 4) Wall, 1200x (Ex: CH8-2 No16). Fig. 11. Pulleniatina obliquiloculata Parker \& Jones 1865; 1) Ventral, 128x (Ex: CH10-2 No13); 2) Dorsal, 130x (Ex: CH10-2 $\left.\mathrm{N}^{\circ} 13\right)$; 3) Lateral, 120x (Ex: CH10-2 $\left.\mathrm{N}^{\circ} 13\right)$; 4) Wall last camera to the figure 1, 1120x (Ex: $\left.\mathrm{CH} 10-2 \mathrm{~N}^{\circ} 13\right)$; 5) Wall last camera to the figure 1, 1120x (Ex: CH10-2 $\left.\mathrm{N}^{\circ} 13\right)$. 
CARACTERÍsticas PRINCIPALES: Conchilla trocoespiral a planiespiral, con enrollamiento dextral o levógiro, superficie híspida con poros pequeños, espinas de corte circular a triangular y luego a trirradial, margen periférico redondeado, largo máximo $0.8 \mathrm{~mm}$. Cámaras globosas. Últimas cámaras elongadas y acuminadas, en juveniles la última vuelta presenta 4-5 cámaras y en adultos 4-6. Abertura umbilical extraumbilical, amplia y profunda, arco bajo con un labio estrecho (Boltovskoy 1981).

Otros aspectos: $G$. calida está estrechamente relacionada a $G$. aequilateralis por la morfología de la conchilla y estructura de las espinas. El estado preadulto y las fases tempranas del adulto son casi indistinguibles (Hemleben et al. 1989)

Esta especie es característica de la zona subtropical (Boltovskoy 1981). Sus máximos de abundancia se encuentran bajo la termoclina, entre los 50 y 100 m de profundidad, debajo de la zona máxima de clorofila (Boltovskoy 1981, Fairbanks et al. 1982, Marchant 1997). A diferencia de N. dutertrei, esta especie responde a cambios de temperatura en la columna de agua y no de la superficie del mar (Fairbanks et al. 1982, Giglio 2001).

Para Coquimbo en condición El Niño, la abundancia relativa de G. calida aumenta de un $4 \%$ a un $7 \%$ aproximadamente, siendo su máximo en condiciones normales en época de surgencia (Marchant 1997, Coloma et al. 2002).

\section{Globigerinella digitata (Brady 1879)}

Globigerina digitata Brady 1879: 599, lám. 80. figs. 6-10; Brady 1884: 599, lám. 80, fig. 6-10 (no la lám. 82, fig. 6-7); Parker 1962: 222, lám. 1 fig. 20-25; Boltovskoy 1981: 339, 348, fig. 168 (7a-c).

Globorotalia (Hastigerinella) digitata Banner \& Blow 1959: 16, text-fig. 4e (lectotipo).

Globorotalia (Beella) digitata Banner \& Blow 1960a: 26, text-fig. 11.

Bella digitata (Brady). Jenkins 1971: 169, lám. 17, figs. 534-535; Kennett \& Srinivasan 1983: 232, lám. 58, figs. 2, 6-8.

Globigerinella digitata (Brady). Hemleben et al. 1989: 18, fig. $2.3 \mathrm{~g}$, h.

Material estudiado: Trampa CH10-2, muestra 17; total ejemplares: 1 .
CARACTERÍSTICA PRINCIPAL: Conchilla trocoespiral alta, con enrollamiento dextral o levógiro, superficie híspida con poros pequeños, espinas delgadas de corte circular, margen periférico redondeado, largo máximo $0.6 \mathrm{~mm}$. Ultima vuelta con 4-6 cámaras. Cámaras inicialmente esféricas, pasando a ovaladas para ser finalmente radialmente elongadas. Abertura interiomarginal, umbilical extraumbilical, arqueada y con labio (Boltovskoy 1981).

OTROS ASPECTOs: Especie rara, aparece en latitudes bajas y medias, aparece a menudo en el mediterráneo, pero parece estar restringida a aguas más profundas, ya que existe una relación bien definida de su abundancia relativa con temperaturas $\left(0-20^{\circ} \mathrm{C}\right)$ de los $200 \mathrm{~m}$ de profundidad (Hemleben et al. 1989). Se registra por primera vez para la zona de Coquimbo $\left(30^{\circ} \mathrm{S}, 73^{\circ} \mathrm{W}\right)$, durante condición El Niño 1997-98, con el mes de septiembre, coincidiendo con un evento de surgencia.

\section{Globigerinella aequilateralis (Brady 1879)}

Figura 18 (Figs. 18.1-18.4)

Globigerina aequilateralis Brady 1879: 285; Brady 1884: 605, lám 80, figs. 18-21; Banner \& Blow 1960a: 23, text-fig. 3a-b.

Hastigerina cf. aequilateralis Brady. Bolli 1957: 108, lám. 22, fig. 1a-2b; Jenkins 1960: 349, lám. 1, fig. 1a-c.

Globigerinella aequilateralis (Brady 1879). Jenkins 1971: 77, lám. 2, fig. 47-9; Boltovskoy 1981: 320, 340, 349, figs. 162 (15) y 168 (27a-c); Kennett \& Srinivasan 1983: 238, lám. 59, fig. 1; lám. 60, figs. 4-6.

Material estudiado: trampa CH10-2, muestras 1, 12, 15, 17-19; CH11-2, muestras 2-5, 10, 14, 18; total ejemplares: 83 .

Museo: UCCC No 26942, 8 ejemplares CH11-2 $\mathrm{N}^{\mathrm{o}} 4>212 \mu \mathrm{m}$.

CARACTERÍSTICA PRINCIPAL: Conchilla trocoespiral, casi planiespiral, con enrollamiento dextral o levógiro, superficie híspida con poros pequeños, espinas de corte circular a triangular y luego a trirradial, margen redondeado, largo redondeado $0.9 \mathrm{~mm}$. Cámaras globosas, última vuelta con 5-6 cámaras. Abertura ecuatorial con reborde fino (Boltovskoy 1981). 
Otros Aspectos: Especie de aguas cálidas propia de la zona subtropical (Bé \& Tolderlund 1971), para condiciones normales aparece hasta los $20^{\circ} \mathrm{S}$ en aguas del Territorio Chileno (Marchant 1997). En condición El Niño esta especie se ha encontrado hasta los $33^{\circ} \mathrm{S}$. Boltovskoy (1976) la incluye en la asociación faunística que vive entre los 31-33 $\mathrm{S}$ (especies de aguas cálidas y frías). Batimétricamente es de aguas intermedias (50$100 \mathrm{~m}$ ) (Boltovskoy 1981). Su límite de tolerancia de temperatura $\left(\mathrm{TSM}^{\circ} \mathrm{C}\right)$ está entre los 12 y $30^{\circ} \mathrm{C}$ (Boltovskoy \& Wright 1976). En cuanto a su ciclo reproductivo, éste es semilunar (Bijma et al. 1990).

Se registra por primera vez para la zona de Coquimbo $\left(30^{\circ} \mathrm{S} ; 73^{\circ} \mathrm{W}\right)$, durante condición El Niño 1997-98.

Globigerinoides ruber (d'Orbigny, 1839) Figura 19 (Figs. 19.1-19.4)

Globigerina rubra d'Orbigny 1839 de la Sagra, Hist. Phys. Pol. Nat. Cuba, "Foraminiferes", 8: 82, lám. 4, figs. 12-14 (fide Jenkins 1971); Banner \& Blow 1960b: 19-20, lám. 3, fig. 8a, b.

Globigerinoides rubra (d'Orbigny). Jenkins 1960: 353, lám. 2, fig. 8a-c, 9a-c.

Globigerinoides ruber (d'Orbigny). Belford 1962: 19, lám 5, figs. 1-6; Bandy \& Rodolfo 1964: 826; Boltovskoy \& Theyer 1970: 370, lám. 6, fig. 5; Jenkins 1971: 177, lám. 21, figs. 616-618; Zapata \& Varela 1975: 17, lám. 2, fig. 4; Boltovskoy 1981: 320, 339, 348, figs. 162 (7) y 168 (8a-c, 9); Zapata \& Castillo 1986: 55, figs. 11-12; Kennett \& Srinivasan 1983: 78, lám. 10, fig. 6; lám. 17, figs. 1-3; Hemleben et al. 1989: 15, fig. 2.2 k, 1; Zapata \& Cea 2002: 64, 69, lám. 2, figs. 5-6.

Material estudiado: Trampa CH10-2, muestras 1-20; trampa CH11-2, muestras 2-20; total ejemplares: 299.

Museo: UCCC $\mathrm{N}^{\circ}$ 26938, 10 ejemplares $\mathrm{CH} 10-2$ $\mathrm{N}^{\mathrm{o}} 17>212 \mu \mathrm{m}$.

CARACTERÍSTICA PRINCIPAL: Conchilla trocoespiral baja, con enrollamiento dextral o levógiro, superficie áspera con poros medianos, espinas de corte circular a levemente triangular, margen periférico redondeado, largo máximo $0.8 \mathrm{~mm}$. Cámaras globosas. Ultima vuelta con 5 cámaras en los juveniles y 3 en los adultos. Abertura umbilical con reborde, abarca las 2 penúltimas cámaras. Con 2 aberturas secundarias (Boltovskoy 1981).

Otros aspectos: También ha sido citada para aguas chilenas, pero no descritas ni figuradas por Boltovskoy \& Watanabe (1975) y Marchantet al. (1998).

Esta especie presenta dos formas: f. rosacea (de paredes rosadas o rojas), y f. alba, siendo esta última unas 5 veces más abundante que la primera. Ambas variedades poseen simbiontes fotosintetizadores, por lo tanto viven en la zona fótica (Boltovskoy 1981). En el área de estudio se encontraron las dos formas. G. ruberes típica de aguas subtropicales, la cual presenta mayor abundancia entre los 0-10 m de profundidad (Bé \& Tolderlund 1971, Boltovskoy 1981). Es por ello que se le puede encontrar en todos los períodos cálidos ya que es sensible a cambios de temperatura más superficial (Giglio 2001). Su distribución vertical en los estadios adultos es entre los 25-37 m de profundidad, en general esta especie es abundante en la zona de mezcla (Steens et al. 1992).

En áreas cálidas la distribución de G. ruber depende más de la salinidad que de la temperatura, siendo su salinidad óptima aquellas menores de 34.5 psu y mayores que 36 psu (Boltovskoy 1981). Boltovskoy \& Wright (1976) indican como salinidad óptima para la f. rosacea 30.5-31 psu y para la f. white 34.5-36 psu, además indican que el límite de tolerancia de temperatura $\left(\operatorname{TSM}^{\circ} \mathrm{C}\right)$ para $G$. ruber está entre los 10.4 y $30^{\circ} \mathrm{C}$. En cuanto a su ciclo reproductivo, éste es semilunar (Bijma et al. 1990).

Globigerinoides sacculifer (Brady 1877)* Figura 20 (Figs. 20.1-20.3)

Globigerina sacculifera Brady 1877: 535; Brady 1879: 287; Brady 1884: 604, lám. 80, figs. 11-17; lám. 82, fig. 4; Banner \& Blow 1960b: 21, lám. 4, fig. 1a-b; lám. 4, fig. 2a, b.

Globigerinoides triloba sacculifera (Brady 1877). Bolli 1957: 113, lám 25, fig. 5a-b, text-fig. 21, nº 4 . 
Globigerinoides quadrilobatus sacculifer (Brady). Parker 1962: 229, lám. 3, figs. 6-10. Globigerinoides trilobus f. sacculifera (Brady). Boltovskoy 1976: 229; Boltovskoy \& Watanabe 1975: 67.

Globigerinoides sacculifer (Brady). Jenkins 1971: 178, lám. 21, figs. 619-621; Boltovskoy 1981: 320, 339, 348, figs. 162 (21) y 168 (12); Kennett \& Srinivasan 1983: 66, lám. 14, figs. 46; Hemleben et al. 1989: 15, 16, fig. $2.2 \mathrm{~m}-\mathrm{r}$; Zapata \& Cea 2002: 64, 69, lám.2. figs. 5-6. Globigerinoides trilobus (Reuss 1850). Hemleben et al. 1989: 15.

* Se mantiene G. sacculifer ya que las formas sacculifer y trilobus de G. trilobus (ver especie siguiente) conviven juntas y a pesar de que los estados juveniles son poco distinguibles, los adultos son fácilmente diferenciados.

Material Estudiado: Trampa CH11-2, muestras 6-13, 15-17; total ejemplares: 42.

Museo: UCCC No 26940, 7 ejemplares CH11-2 $\mathrm{N}^{\circ} 8>212 \mathrm{~mm}$.

CARACTERÍSTICA PRINCIPAL: Conchilla trocoespiral baja, enrollamiento dextral o levógiro, superficie de aspecto apanalado (con forma de panal de abejas) con poros grandes, espinas de corte circular levemente triangular, margen periférico redondeado, largo máximo $1.3 \mathrm{~mm}$. Cámaras de forma globosa, la última elongada y/o sacciforme, última vuelta con 6-7 cámaras en juveniles y en adultos 4 . Abertura umbilical con reborde. Con una abertura secundaria por cámara (Boltovskoy 1981).

Otros AsPectos: Especie de aguas cálidas, propia de la zona tropical, llegando en condiciones normales hasta los $20^{\circ} \mathrm{S}$ (Boltovskoy 1976). Boltovskoy \& Watanabe (1975) la citan para el área de Isla de Pascua, Chile. En áreas cálidas, la distribución de esta especie depende más de la salinidad que de la temperatura al igual que Globigerinoides ruber, pero en el caso de $G$. sacculifer la salinidad óptima es entre 34.5 psu y 36 psu (Boltovskoy 1981). El límite de tolerancia de temperatura $\left(\mathrm{TSM}^{\circ} \mathrm{C}\right)$ para esta especie está entre los 15 y $30^{\circ} \mathrm{C}$ (Boltovskoy \& Wright 1976). En cuanto a su ciclo reproductivo, este es lunar (Bijma et al. 1990).
Se registra por primera vez en la zona de Coquimbo para El Niño 1997-98.

\section{Globigerinoides trilobus (Reuss 1850)}

Figura 21 (Figs.21.1-21.4)

Globigerina triloba Reuss 1850: 374, lám. 447, figs. 11a-c; Chapman 1926: 73, lám. 14, fig. 18 (fide Jenkins 1971).

Globigerinoides triloba (Reuss). Finlay \& Marwick 1940: 119; Blow 1956: 62, text-fig. 1, no 1-3; Hornibrook 1958: 29-31; Kennett \& Srinivasan 1983: 62, lám. 10, fig. 4; lám. 13, figs. 1-3.

Globigerinoides triloba triloba (Reuss). Bolli 1957: 112, lám. 25, fig. 2a-c, text-fig. 21, $\mathrm{n}^{\circ} 1$. [error por trilobus trilobus]

Globigerinoides quadrilobatus d'Orbigny 1846 In Banner \& Blow 1960b: 17, lám. 4, fig. 3.

Globigerinoides triloba (Reuss) subsp. triloba: Jenkins 1960: 353, lám. 2, fig. 5a-c.

Globigerinoides triloba (Reuss)subsp. inmatura Le Roy 1839 In Jenkins 1960: 354, lám. 2, fig.7a-c; Kennett \& Srinivasan 1983: 64, lám. 10, fig. 3; lám 13, figs. 7-9.

Globigerinoides trilobus trilobus (Reuss). Jenkins 1971: 180, lám. 19, figs. 571-581.

Globigerinoides trilobus(Reuss). Boltovskoy 1976: 229; Boltovskoy 1981: 320, 339, 348, figs. 162 (8) y 168 (11a-b).

Material estudiado: Trampa CH11-2, muestras 3, 6-14, 17; total ejemplares: 36

Museo: UCCC No 26941, 2 ejemplares CH10-2 $\mathrm{N}^{\mathrm{o}} 11>212 \mathrm{~mm}$.

Característica Principal: Conchilla trocoespiral baja, enrollamiento dextral o levógiro, superficie de aspecto apanalado con poros grandes, espinas de corte circular levemente triangular, margen periférico redondeado, largo máximo $1 \mathrm{~mm}$. Cámaras de forma globosa, última vuelta con 6-7 cámaras en juveniles y 3 en adultos. Abertura umbilical con reborde, abarcando las 3 cámaras precedentes. Con una abertura secundaria por cámara (Boltovskoy 1981).

Otros Aspectos: G. trilobus es una especie de aguas cálidas propia de la zona tropical (Boltovskoy 1976). 
El límite de tolerancia de temperatura $\left(\mathrm{TSM}^{\circ} \mathrm{C}\right)$ para esta especie está entre los 13 y $30^{\circ} \mathrm{C}$ (Boltovskoy \& Wright 1976).

Se registra por primera vez en la zona de Coquimbo para El Niño 1997-98.

Turborotalita humilis (Brady 1884) Figura 22 (Figs. 22.1-22.4)

Truncatulina humilis Brady 1884: 665, lám. 94, fig. 7.

Globigerina sp. Cushman \& Wickenden 1929: 13, lám. 5, fig. 7.

Globigerinita humilis (Brady). Boltovskoy 1976: 229; Boltovskoy 1981: 342, 349, fig. 168 (32a-b); Zapata \& Castillo 1986: 54, figs. 9-10.

Turborotalita humilis (Brady). Kennett \& Srinivasan 1983: 167, lám. 41, figs. 1, 3-5; Hemleben et al. 1989: 13, fig. $2.1 \mathrm{n}-\mathrm{p}$.

Material Estudiado: Trampa CH10-2, muestras 3, 8, 19; trampa CH11-2, muestras 2-5, 7, 8, 11; total ejemplares: 13.

Museo: UCCC N²6944, 2 ejemplares CH11-2 Nº $>212 \mu \mathrm{m}$.

CAracterística Principal: Conchilla pequeña con forma trocoespiral aplanada, enrollamiento dextral y levógiro, superficie finamente híspida con poros grandes, carece de espinas, margen periférico redondeado, largo máximo $0.2 \mathrm{~mm}$. Cámaras hemiesféricas, la última con una gran expansión lobulada ventralmente, última vuelta con 5-6 cámaras en juveniles y 6-8 en adultos. Abertura umbilical, a veces infralaminar, con reborde (Boltovskoy 1981).

Otros Aspectos: Vive en la zona fótica de aguas subtropicales, temperadas (Kemle-von Mücke \& Hemleben 1999). Se conoce muy poco sobre esta especie.

\section{Turborotalita quinqueloba (Natland 1938)}

Globigerina quinqueloba Natland 1938: 149, lám. 6. Figs. 18-21; Boltovskoy 1976: 229; Boltovskoy 1981: 339, 348, fig. 168 (5a-c); Parker 1962: 225, lám. 2, figs. 7-16; Jenkins 1964: 26, text-fig; Hulme
1964: 335, fig. 5, nos. 1-11; fig. $6, \mathrm{n}^{\text {o }}$. 1-2.

Globigerina groenlandica Scedrina 1946: 145, lám.4, fig. 23a, b (fide Jenkins 1971).

Globigerina weissi Saito 1963: 188, lám. 54, figs. 13a-14.

Globigerina atlantisae Cifelli \& Smith 1970: 52.

Globigerina (Globigerina) quinqueloba Natland). Kennett \& Srinivasan 1983: 32, lám. 5, figs. 4-6; Jenkins 1971: 155, lám. 18, figs. 539-544.

Turborotalita quinqueloba (Natland). Hemlebenet al. 1989: 13, fig. 2.2 a-f.

Material estudiado: Trampa CH10-2, muestras 18, 11-20; trampa CH11-2, muestras 2-15, 17-20; total ejemplares: 1.074 .

Museo: UCCC No 26943, 10 ejemplares CH11-2 $\mathrm{N}^{\circ} 4>212 \mu \mathrm{m}$.

CARACTERÍstica PRINCIPAL: Conchilla trocoespiral baja, enrollamiento dextral o levógiro, superficie híspida, poros pequeños, espinas delgadas de corte circular, margen redondeado, largo máximo $0.3 \mathrm{~mm}$. Cámaras globosas, la última frecuentemente con una expansión lobulada en el lado ventral. Ultima vuelta con 5-6 cámaras. Abertura umbilical, elongada con labio (Boltovskoy 1981).

Otros aspectos: $T$. quinqueloba es una especie propia de las zonas subártica y subantártica (Bé \& Tolderlund 1971). El límite de tolerancia de temperatura $\left(\mathrm{TSM}^{\circ} \mathrm{C}\right)$ para esta especie está entre los -1 y $25^{\circ} \mathrm{C}$, esta especie es más abundante en salinidades entre 30.5 y 31 psu (Boltovskoy 1976 , Boltovskoy \& Wright 1976). Batimétricamente, se le encuentra en aguas superficiales (0-10-50 m) (Marchant 1997, Boltovskoy 1981). En cuanto a la reproducción Hemleben et al. (1989), sugieren que posee ciclo semilunar. Esta especie tiende a aumentar la proporción de ejemplares levógiros con la disminución de las temperaturas (Boltovskoy 1981, Carstens \& Wefer 1992).

La mayor abundancia de $T$. quinqueloba en el área de estudio ha sido durante la condición de El Niño, tanto 1991-92 como 1997-98, relacionándose con eventos de surgencia; en condiciones normales, esta especie ha aparecido ocasionalmente siendo más común con las surgencias (El Niño 1991-92 y Condición Normal: Marchant et al. 1998, Giglio 2001). 
「istural?

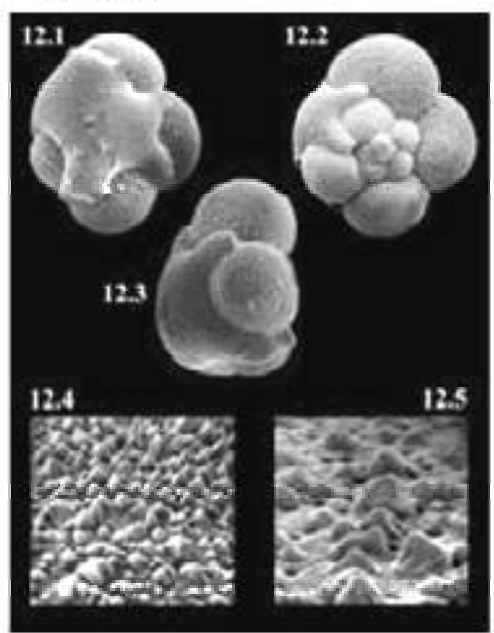

Figura 15

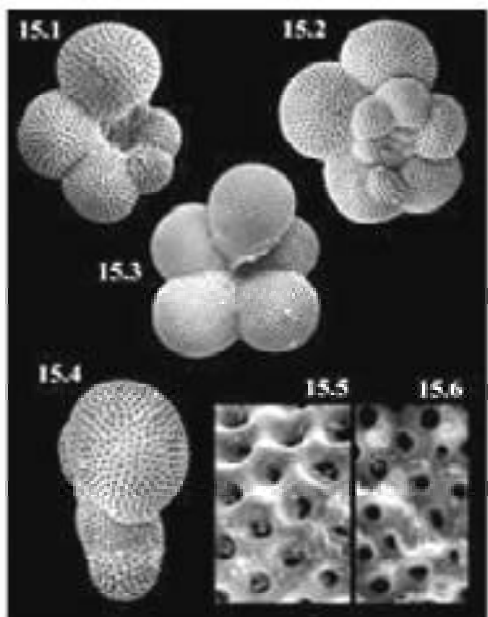

Figur: 18

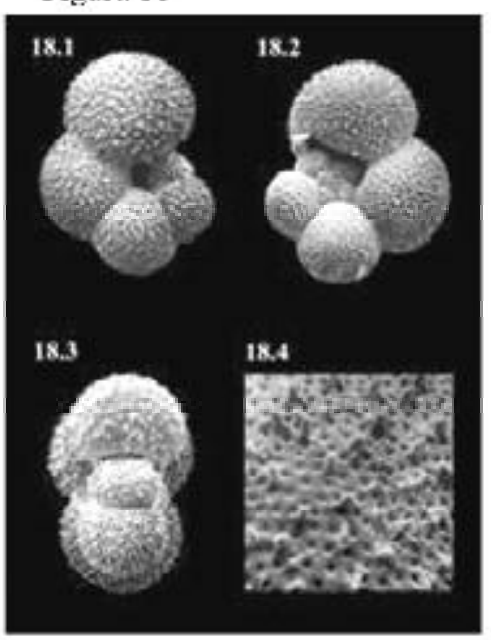

Figura 13

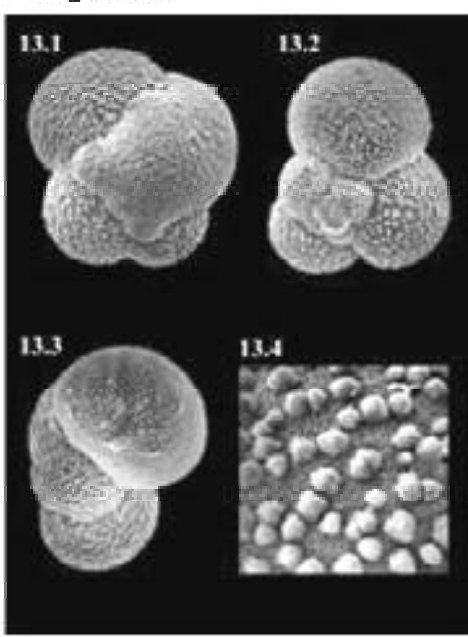

Figura 16

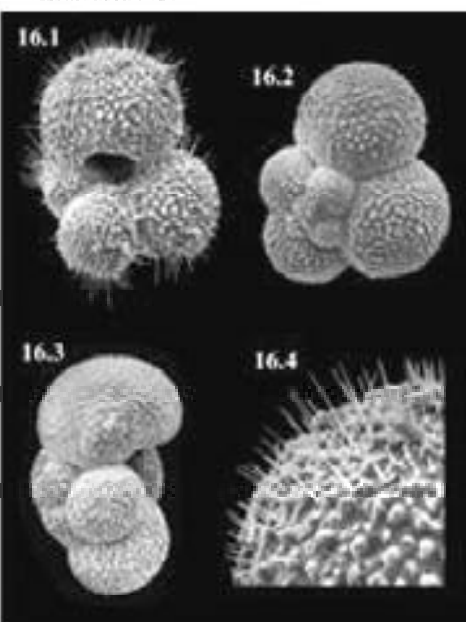

Figura 19

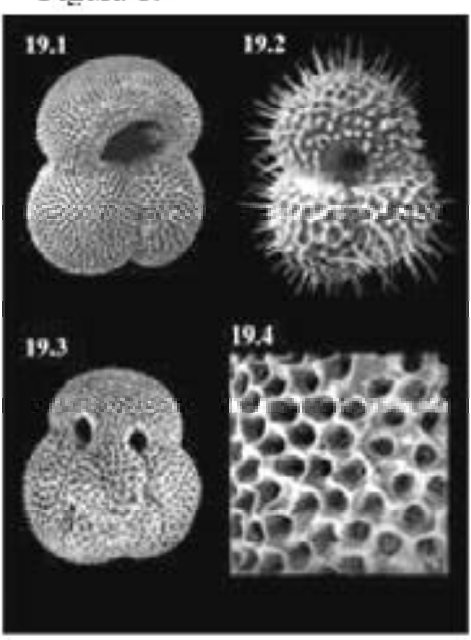

Figure 14

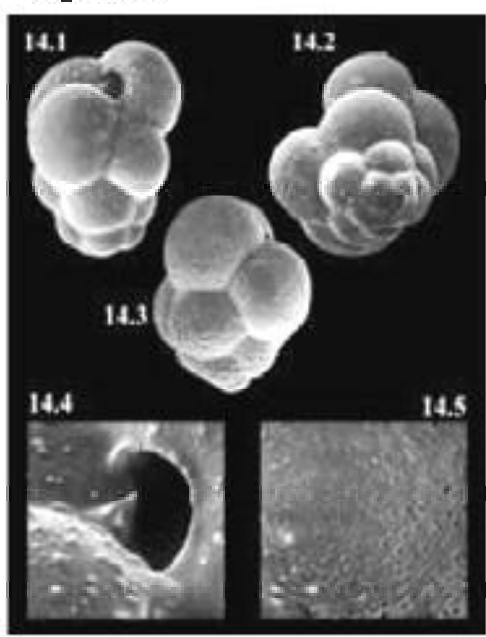

Fivgra 17

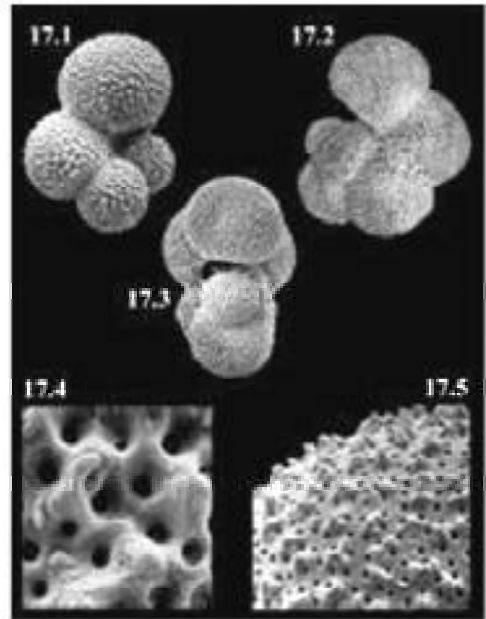

Firura 20

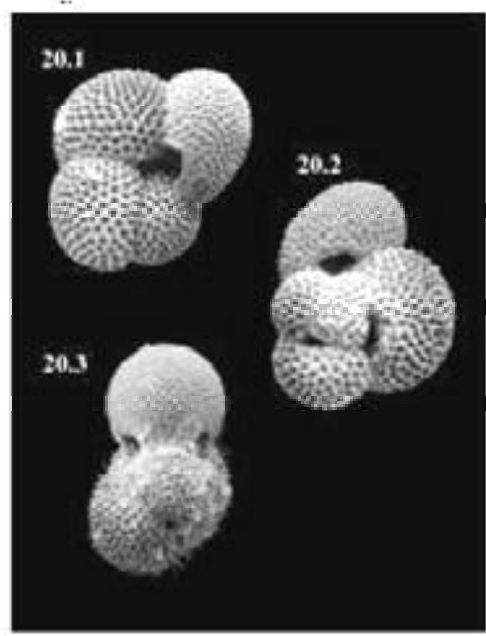


Orbulina universa d'Orbigny 1839

Figura 23 (Figs. 23.1-23.3)

Orbulina universa d'Orbigny 1839 de la Sagra, Hist. Phys. Pol. Nat. Cuba, "Foraminiferes", 8: 2, lám. 1, fig. 1 (fide Jenkins 1971); Brady 1884: 608, lám 78 (1), lám. 81 (8, 26), lám 82 (1-3); Blow 1956: 66, text-fig. 2, nos.8-9; Bolli 1957: 115, lám. 27, fig. 5; Blow 1959: 200, lám. 13, fig. 83; Carter 1959: 53, fig. 51; Jenkins 1960: 356, lám. 3, fig. 12; Bandy \& Rodolfo 1964: 826; Boltovskoy \& Theyer 1970: 371, lám. 6, fig. 6; Jenkins 1971: 193, lám. 23, fig. 660; Boltovskoy 1976: 230; Boltovskoy 1981: 341, 348, fig. 168 (16); Zapata \& Castillo 1986: 55, fig. 13; Kennett \& Srinivasan 1983: 86, lám. 18, fig. 2; lám. 20, figs. 4-6; Hemleben et al. 1989: 19, fig. 2.3 1, m;
Zapata \& Cea 2002: 65, 70, lám. 3, fig. 2. Biorbulina bilobata (d'Orbigny 1846). Blow 1956 :

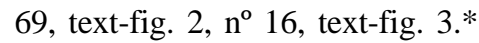

*En cuanto a Biorbulina bilobata (d'Orbigny), ésta corresponde a un estado de desarrollo de $O$. universa (Jenkins 1971).

Material estudiado: Trampa CH10-2, muestras 12, 4, 6, 8-10, 12-20; trampa CH11-2: muestras 220; total ejemplares: 287.

Museo: UCCC N²6935; 10 ejemplares CH10-2 $\mathrm{N}^{\circ} 17>212 \mathrm{~mm}$.

CARACTERÍSTICA PRINCIPAL: En juveniles la conchilla posee forma trocoespiral, en los adultos es esférica.

Figuras 12-20. Fig. 12. Tenuitella iota (Parker 1962); 1) Ventral, 320x (Ex: CH10-2 No15); 2) Dorsal, 300x (Ex: CH10$\left.2 \mathrm{~N}^{\circ} 15\right)$; 3) Lateral, 340x (Ex: CH10-2 No15); 4) Pared última cámara de la figura 2, 4000x (Ex: CH10-2 No15); 5) Detalle pared de la figura 2, 4400x (Ex: CH10-2 No15). Fig. 13. Globigerinita glutinata (Egger 1893). 1) Ventral, 300x (Ex: CH8-2 No6); 2) Dorsal, 200x (Ex: CH8-2 No6); 3) Lateral, 200x (Ex: CH8-2 N6); 4) Pared, 1600x (Ex: CH8-2 №6). Fig. 14.Globigerinita uvula (Ehrenberg 1861); 1) Umbilico-lateral, 440x (Ex: CH11-2 №4); 2) Dorsal, 560x (Ex: CH11-2 No4); 3) Lateral, 560x (Ex: CH11-2 No4); 4) Detalle abertura, 2200x (Ex: CH11-2 No4); 5) Pared última cámara, 2200x (Ex: CH11-2 No4). Fig. 15. Globorotaloides hexagonus (Natland 1938); 1) Ventral, 225x (Ex: CH10-2 No17); 2) Dorsal, 200x (Ex: CH5-2 No9); 3) Ventral, 150x (Ex: CH10-2 Nº17); 4) Lateral, 280x (Ex: CH5-2 No9); 5) Pared última cámara de la figura 4, 2000x (Ex: CH5-2 N9); 6) Pared segunda cámara de la figura 4, 2000x (Ex: CH5-2 N9). Fig. 16. Globigerina bulloides d'Orbigny 1826; 1) Ventral, 240x (Ex: CH5-2 №1); 2) Vista dorsal, 220x (Ex: CH5-2 №1). 3) Lateral, 220x (Ex: CH5-2 ํo1); 4) Pared última cámara de la figura 1, 960x (Ex: CH5-2 №1). Fig. 17. Globigerinella calida (Parker 1962); 1 Ventral, 200x (Ex: CH10-2 No5); 2 Dorsal, 160x (Ex: CH5-2 No2); 3) Lateral, 160x (Ex: CH5$2 \mathrm{~N}^{\circ}$ ); 4) Detalle pared última cámara de la figura 3, 2600x (Ex: CH5-2 №2); 5) Pared última cámara de la figura 1, 840x (Ex: CH10-2 No5). Fig. 18. Globigerinella aequilateralis (Brady) 1879; 1) Ventral, 143x (Ex: CH11-2 No 10); 2) Dorsal, 130x (Ex: CH11-2 No10); 3. Lateral, 200x (Ex: CH11-2 No14); 4) Vista pared, 800x (Ex: CH11-2 No10). Fig. 19. Globigerinoides ruber (d'Orbigny 1839); 1) Ventral, 160x (Ex: CH8-2 Nº); 2) Ventral de un juvenil, 280x (Ex: CH11$2 \mathrm{~N}^{\circ} 2$ ); 3) Dorsal, 200x (Ex: CH8-2 No6); 4). Detalle pared cámara última de la figura 3, 800x (Ex: CH8-2 No6). Fig. 20. Globigerinoides sacculifer (Brady 1877); 1) Ventral, 160x (Ex: CH11-2 ํo7); 2). Dorsal, 160x (Ex: CH11-2 Nº); 3) Lateral, 120x (Ex: CH11-2 No 7 ).

Figures 12-20. Fig. 12. Tenuitella iota (Parker 1962); 1) View, 320x (Ex: CH10-2 No 15); 2) Dorsal, 300x (Ex: CH10-2 $\left.\mathrm{N}^{\circ} 15\right)$; 3) Lateral, 340x (Ex: CH10-2 $\left.\mathrm{N}^{\circ} 15\right)$; 4) Wall last camera to the figure 2, 4000x (Ex: CH10-2 $\left.\mathrm{N}^{\circ} 15\right)$, 5) Detail wall to the figure 2, 4400x (Ex: CH10-2 No15). Fig. 13. Globigerinita glutinata (Egger 1893); 1 Ventral, 300x (Ex: CH8-2 $\mathrm{N}^{\circ}$ 6); 2) Dorsal, 200x (Ex: CH8-2 No6); 3) Lateral, 200x (Ex: CH8-2 No6); 4) Wall, 1600x (Ex: CH8-2 No6). Fig. 14. Globigerinita uvula (Ehrenberg 1861); 1) Umbilicus-lateral view, 440x (Ex: CH11-2 No4); 2) Dorsal, 560x (Ex: CH11$\left.2 \mathrm{~N}^{\circ} 4\right)$; 3) Lateral, 560x (Ex: CH11-2 No4); 4) Detail to the opening, 2200x (Ex: CH11-2 No4); 5) Wall last camera, 2200x (Ex: CH11-2 №4). Fig. 15. Globorotaloides hexagonus (Natland 1938); 1) Ventral, 225x (Ex: CH10-2 No17); 2) Dorsal, 200x (Ex: CH5-2 No9); 3) Ventral, 150x (Ex: CH10-2 ํo17); 4) Lateral, 280x (Ex: CH5-2 N9); 5) Wall last camera to the figure 4, 2000x (Ex: CH5-2 No9); 6) Wall second camera to the figure 4, 2000x (Ex: CH5-2 No9). Fig. 16. Globigerina bulloides d'Orbigny 1826; 1) Ventral, 240x (Ex: CH5-2 No 1); 2) Dorsal, 220x (Ex: CH5-2 Nº1); 3) Lateral, 220x (Ex: CH5-2 No1); 4) Wall last camera to the figure 1, 960x (Ex: CH5-2 №1). Fig. 17. Globigerinella calida (Parker 1962); 1) Ventral, 200x (Ex: CH10-2 No5); 2) Dorsal, 160x (Ex: CH5-2 oo2); 3) Lateral, 160x (Ex: CH5-2 No2); 4) Detail wall last camera to the figure 3, 2600x (Ex: CH5-2 No2); 5) Wall last camera to the figure 1, 840x (Ex: CH10-2 №5). Fig. 18. Globigerinella aequilateralis (Brady 1879); 1) Ventral, 143x (Ex: CH11-2 No10); 2 Dorsal, 130x (Ex: CH11-2 No10); 3) Lateral, 200x (Ex: CH11-2 No14); 4) Wall, 800x (Ex: CH11-2 No10). Fig. 19. Globigerinoides ruber (d'Orbigny 1839); 1) Ventral, 160x (Ex: CH8-2 No6); 2) Ventral of the juvenile, 280x (Ex: CH11-2 N²); 3) Dorsal, 200x (Ex: CH8-2 No6); 4) Detail wall last camera to the figure 3, 800x (Ex: CH8-2 No6). Fig. 20. Globigerinoides sacculifer (Brady 1877); 1) Ventral, 160x (Ex: CH11-2 No7); 2) Dorsal, 160x (Ex: CH11-2 No7); 3) Lateral, 120x (Ex: CH11-2 No7). 
Figura 21

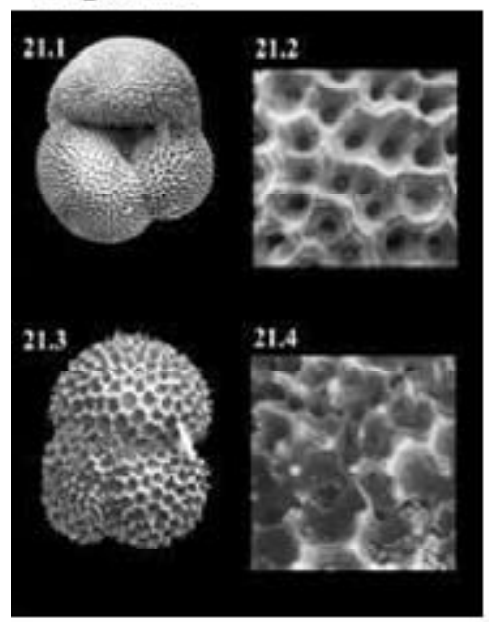

Figura 23

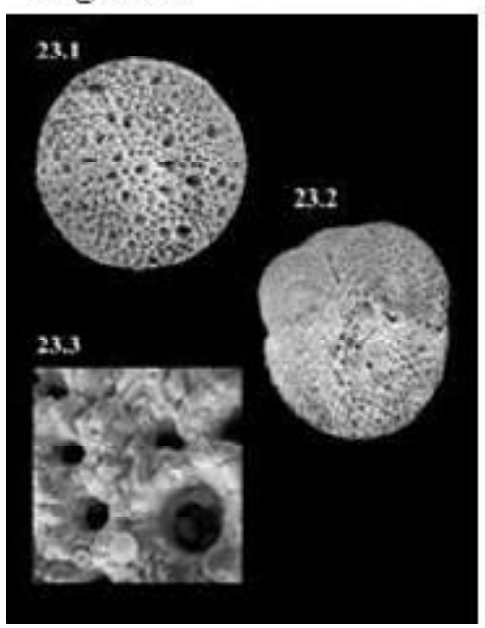

Figura 22

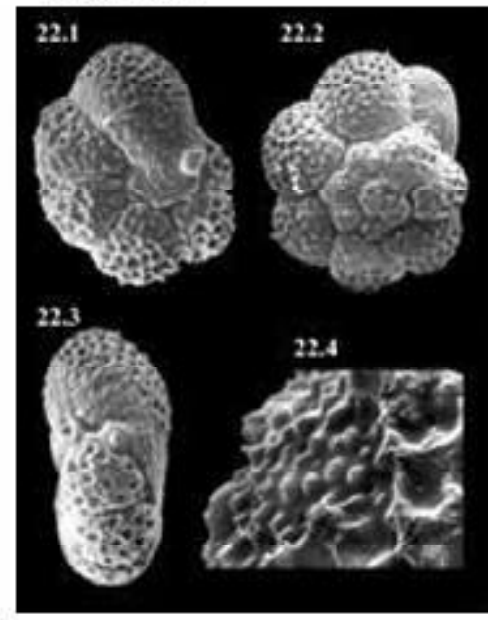

Figura 24

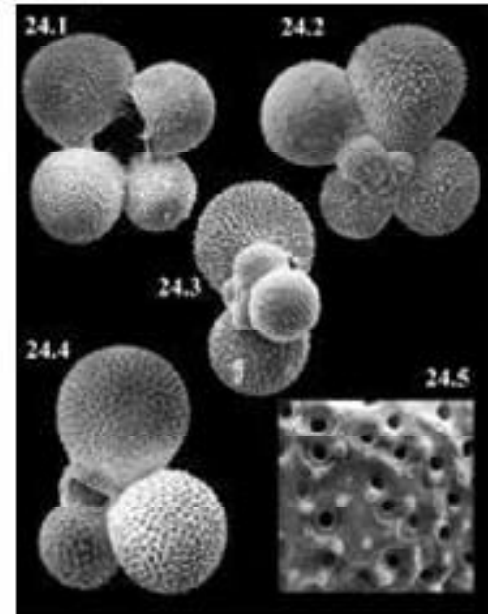

FiguRas 21-24. Fig. 21. Globigerinoides trilobus (Reuss 1850); 1) Ventral, 120x (Ex: CH11-2 №4); 2) Pared de la figura 1, 900x (Ex: CH11-2 №4); 3) Dorsal, 195x (Ex: CH11-2 ํo7); 4) Pared de la figura 3, 900x (Ex: CH11-2 No7). Fig. 22. Turborotalita humilis (Brady 1884); 1) Ventral, 400x (Ex: CH11-2 No1); 2) Vista dorsal, 400x (Ex: CH11-2 No2); 3) Lateral, 400x (Ex: CH11-2 №3); 4) Pared, 2000x (Ex: CH11-2 №2). Fig. 23. Orbulina universa d'Orbigny 1839; 1) Adulto, 200x (Ex: CH5-2 No8); 2) Juvenil trilocular, 203x (Ex: CH5-2 No 8); 3) Pared, 1600x (Ex: CH8-2 No16). Fig. 24. Hastigerina digitata (Rhumbler 1911); 1) Ventral, 160x (Ex: CH11-2 N¹6); 2) Dorsal, 200x (Ex: CH11-2 No16); 3) Lateral, 255x (Ex: CH11-2 No16); 4) Ventral, 255x (Ex: CH11-2 No16); 5) Pared, 900x (Ex: CH11-2 Nº16).

Figures 21-24. Fig. 21. Globigerinoides trilobus (Reuss 1850); 1) Ventral, 120x (Ex: CH11-2 No4); 2) Wall view to the figure 1, 900x (Ex: CH11-2 No4); 3) Dorsal, 195x (Ex: CH11-2 No7); 4) Wall view to the figure 3, 900x (Ex: CH11-2 $\mathrm{N}^{\circ} 7$ ); Fig. 22. Turborotalita humilis (Brady 1884); 1) Ventral, 400x (Ex: CH11-2 No1); 2) Dorsal, 400x (Ex: CH11-2 $\mathrm{N}^{\circ}$ 2); 3) Lateral, 400x (Ex: CH11-2 No3); 4) Wall view, 2000x (Ex: CH11-2 No2). Fig. 23. Orbulina universa d'Orbigny 1839; 1) Adult, 200x (Ex: CH5-2 No8); 2) Trilobate juvenile, 203x (Ex: CH5-2 No8); 3) Wall view, 1600x (Ex: CH8-2 $\mathrm{N}^{\circ}$ 16). Fig. 24. Hastigerina digitata (Rhumbler 1911); 1) Ventral, 160x (Ex: CH11-2 No16); 2) Dorsal, 200x (Ex: CH11-2 No16); 3) Lateral, 255x (Ex: CH11-2 No16); 4) Ventral view, 255x (Ex: CH11-2 Nº16); 5) Wall view, 900x (Ex: CH11-2 No16). 
Superficie lisa con poros pequeños y grandes, espinas de corte circular, pasando a triangular y luego a trirradial, largo máximo $1 \mathrm{~mm}$. Cámara esférica, en juveniles con 4-5 cámaras, en adultos sólo una. En juveniles presenta abertura umbilical, adultos sin una abertura principal (Boltovskoy 1981).

Otros Aspectos: En cuanto a su distribución, $O$. universa está ampliamente distribuida desde las zonas tropicales a subpolares. En cuanto a la salinidad tolera entre los 23 y 46 psu y la temperatura entre 10 y $30^{\circ} \mathrm{C}$ (Boltovskoy 1981, Boltovskoy \& Wright 1976). Batimétricamente es de aguas intermedias (50-100 m) (Boltovskoy 1981). Se le encuentra con mayor frecuencia en sistemas de corrientes fuertes y regiones de surgencias próximos al margen continental (Bé \& Tolderlund 1971). La talla está correlacionada con la temperatura y el alimento, en su estado adulto esférico es netamente carnívoro, mientras que en su estadio juvenil es herbívoro (Boltovskoy \& Wright 1976). En cuanto a su ciclo reproductivo, éste es lunar (Boltovskoy 1981, Bijma et al. 1990).

\section{Hastigerina digitata (Rhumbler 1911) \\ Figura 24 (Figs. 24.1-24.5)}

Hastigerina digitata Rhumbler 1911: 202, lám. 37, figs. 9, 10.

Hastigerinella digitata (Rhumbler). Boltovskoy 1976, 230; Boltovskoy 1981: 340, 349, fig. 168 (20).

Hastigerina digitata (Rhumbler). Hemleben et al. 1989: 19, 20, fig. 2.3 p, q.

Material estudiado: Trampa CH10-2, muestras 2, 8, 13-20; trampa CH11-2, muestra 2; total ejemplares: 509 .

Museo: UCCC No 26937; 10 ejemplares CH10-2 $\mathrm{N}^{\mathrm{o}} 17>212 \mu \mathrm{m}$.

CARACTERÍstica PRINCIPAL: Conchilla planiespiral a estreptoespiral, superficie lisa, translúcidas, con poros pequeños, espinas de corte trirradial, margen periférico redondeado, largo máximo $5 \mathrm{~mm}$. Cámaras bifurcadas o trifurcadas. Ultima vuelta con 6 cámaras. Abertura con reborde, de posición ecuatorial, transformándose en espiroumbonal (Boltovskoy 1981).

Otros Aspectos: Especie de aguas profundas. Vive en la zona fótica cuando joven y desciende a profundidades mayores de $100 \mathrm{~m}$ al madurar (Boltovskoy 1981).

Se registra por primera vez esta especie para la zona de Coquimbo $\left(30^{\circ} \mathrm{S}, 73^{\circ} \mathrm{W}\right)$ durante condición El Niño 1997-98.

\section{CLAVE DICOTOMICA DE FORAMINIFEROS PLANCTONICOS PRESENTES EN EL AREA DE COQUIMBO, CHILE}

Clave basada en los caracteres principales según Boltovskoy (1981), Kennett \& Srinivasan (1983) y Hemleben et al. (1989).

1. Caparazón multilocular, con o sin espinas …................................................................ 2 trilocular con abertura secundaria), con espinas Orbulina universa

2. Caparazón planiespiral o estreptospiral

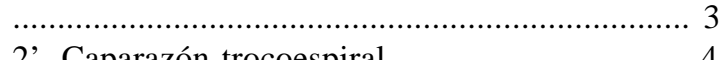

2'. Caparazón trocoespiral ................................ 4

3. Caparazón planiespiral ........ Hastigerina digitata 3'. Caparazón estreptospiral Pulleniatina obliquiloculata

4. Caparazón espinoso 5

4'. Caparazón no espinoso ……......................... 13

5. Caparazón trocoespiral en un plano ................ 6

5'. Caparazón trocoespiral bajo o alto ............ 8

6. Caparazón trocoespiral aplanado, con 5-6 cámaras hemiesféricas en juveniles y 6-8 en adultos, la última con expansión sobre la abertura

Turborotalita humilis

6'. Caparazón trocoespiral llegando a ser planiespiral, con 4-6 cámaras globosas

7. Caparazón simétrico (equilateral), con 5-6 cámaras, con abertura ecuatorial con reborde fino Globigerinella aequilateralis 
7'. Caparazón asimétrico, con 5 cámaras en juveniles y 4-6 en adultos, con abertura umbilical extraumbilical, sin reborde ni labio... Globigerinella calida

8. Caparazón trocoespiral bajo

8'. Caparazón trocoespiral alto, con 4-6 cámaras digitadas Globigerinella digitata

9. Carece de abertura(s) secundaria(s) 10

9'. Con abertura(s) secundaria(s) 11

10. Con 5-6 cámaras, la última con labio en el lado ventral tapando la abertura, esta última con reborde Turborotalita quinqueloba

10'. Con 4-5 cámaras, abertura grande, sin labio, abarcando las 3 cámaras anteriores

Globigerina bulloides

11. Con 1 abertura secundaria por cámara .. 12 11'. Con 2 aberturas secundarias por cámara, abertura principal abarca las 2 cámaras anteriores Globigerionoides ruber

12. Con 6-7 cámaras sacciformes en juveniles y 4 en adultos, pared con forma de panal, última cámara elongada con su abertura secundaria tan grande como la principal ............... Globigerinoides sacculifer 12'. Con 6-7 cámaras globosas en juveniles y 3 en adultos, pared con forma de panal, abertura principal con forma de hojal abarcando las 3 cámaras precedentes Globigerinoides trilobus

13. Conchilla trocoespiral alta, racimosa, pequeña, de cámaras globosas y poros pequeños. Abertura umbilical, con/sin labio pequeño Globigerinita uvula

13'. Conchilla trocoespiral baja o aplanada 14

14. Conchilla trocoespiral baja 15

14'. Conchilla trocoespiral aplanada, aplanada cónica o convexa .. 18

15. Cámaras globosas 16

15'. Cámaras subglobosas compactas 17

16. Con 5 (juv.) a 4 cámaras (ad.) globosas de superficie casi lisa, con poros pequeños. Abertura umbilical, frecuentemente infralaminal (con bulla), con labio grande

Globigerinita glutinata 16'. Con 5-6 (juv.) a 4-6 cámaras (ad.) subglobosas grandes, escrobiculadas, de poros medianos. Abertura umbilical grande con dientes.

.. Neogloboquadrina dutertrei 17. Conchilla de enrollamiento hacia la derecha (dextral), de margen redondeado, con 41/2-5 cámaras subglobosas de poros medianos. Abertura umbilical extraumbilical dextral, con labio Neogloboquadrina incompta 17' Conchilla de enrollamiento hacia la izquierda (levógira), de margen redondeado, con 4 cámaras subglobosas de poros medianos. Abertura umbilical extraumbilical dextral, con labio

Neogloboquadrina pachyderma

18. Conchilla aplanada 19

18'. Conchilla aplanada convexa o aplanada cónica

19. Margen periférico redondeado con 4-5 cámaras .. 20

19'. Margen periférico con quilla con 5-6 cámaras

21

20. Con 5 (juv.) a 4-5 (ad.) cámaras subglobosas, con poros muy pequeños, última cámara alargada con forma de mano tapando la abertura principal. Abertura umbilical extraumbilical con labio delgado. Aberturas secundarias infralaminares de la última cámara. Pequeño tamaño $(<180 \mu \mathrm{m})$

Tenuitella iota

20'. Con 5 cámaras muy aplanadas de pared escrobiculada, con poros medianos. Abertura umbilical casi extraumbilical con labio. Gran tamaño $(200 \mu \mathrm{m})$ Globorotaloides hexagonus

21. Cámaras angulosas romboidales. Abertura umbilical extraumbilical grande con labio

Globorotalia menardii

21'. Cámaras angulosas romboidales, de pared más gruesa y espira más alta que G. menardii, con poros muy pequeños. Última cámara un poco doblada hacia el lado ventral. Abertura umbilical extraumbilical con labio Globorotalia tumida

22. Conchilla aplanada convexa ....................... 23

22'. Conchilla planocónica 24

23. Conchilla convexa biconvexa, con 5-6 cámaras angulosas romboidales, con poros medianos, de margen periférico redondeado. Abertura umbilical 
extraumbilical con labio Globorotalia scitula 23'. Conchilla convexa desigualmente biconvexa, con 4-5 cámaras angulosas romboidales, con poros pequeños, margen periférico con quilla discontinua. Abertuta umbilical extraumbilical con labio delgado Globorotalia theyeri

24. Conchilla planocónica 25

24'. Conchilla planocónica redondeada de 5 (juv.) a 4 (ad.) cámaras hemiesféricas infladas, con poros muy pequeños. Margen periférico redondeado. Abertura umbilical extraumbilical con reborde. Lado ventral de la conchilla convexo, lado dorsal plano Globorotalia inflata

25. Con 6 (juv.) a 5-51/2 (ad.) cámaras angulosas cónicas, margen periférico con quilla limbada, poros pequeños. Abertura extraumbilical con labio. Globorotalia truncatulinoides 25'. Con 5-6 (juv.) a 4-5 (ad.) cámaras angulosas cuadrado-cónicas, margen periférico con quilla de contorno anguloso, poros muy pequeños. Abertura extraumbilical con labio

Globorotalia crassaformis

\section{DISCUSION}

Para el área de Coquimbo se ha registrado un máximo de 26 especies de foraminíferos planctónicos, variando su número en el tiempo según sea Condición Normal o El Niño en la zona. El máximo de especies se registró en este estudio, El Niño 1997-98 (26), comparado con El Niño 1991-92 (19) y el mínimo para Condición Normal 1993-94 (17) (Marchant et al. 1998, Hebbeln et al. 2000). Debido a que la condición La Niña no ha sido registrada entre 1991 a 1998 (Marchant et al. 1998, Marchant et al.: In litteris) en el área de estudio, no se encuentran datos sobre el número de especies durante esta condición. Durante El Niño 1997-98 se encontraron 7 especies más que en El Niño 1991-92, de las cuales 6 son de aguas cálidas (Globigerinoides sacculifer, Globigerinoides trilobus, Globigerinella digitata, Hastigerina digitata, G. theyeri, G. tumida) y una de aguas frías (Globigerinita uvula), relacionándose las primeras 6 especies con surgencias de aguas cálidas y Globigerinita uvula con surgencias de aguas antárticas y/o subantárticas.

De las 9 especies de aguas cálidas encontradas en el presente estudio (Globigerinoides sacculifer, Globigerinoides trilobus, Globigerinella aequilateralis, G. digitata, Hastigerina digitata, Globorotalia crassaformis, G. theyeri, G. tumida y Pulleniatina obliquiloculata), 3 de ellas (Globigerinella aequilateralis, Globorotalia crassaformis y Pulleniatina obliquiloculata) se registraron por primera vez a la latitud de Coquimbo con el evento El Niño 1991-92, las cuales fueron consideradas como indicadoras de este evento por Marchant et al. (1998).

De las 5 especies más abundantes en el área de estudio, Marchant et al. (1998) considera a $N$. dutertrei indicadora del evento El Niño 1991-92, debido al incremento en su abundancia durante este período en comparación con el resto de las especies, lo cual se repite en el evento El Niño 1997-98.

De la revisión taxonómica de sinonimias y nuevas combinaciones de las especies encontradas se realizaron los siguientes cambios:

- Neogloboquadrina pachyderma (Ehrenberg 1861):

En el caso de esta especie, cuya conchilla presenta enrollamiento hacia la derecha e izquierda, Boltovskoy (1976) encontró que estas formas se separaban a los $33^{\circ} \mathrm{S}$, siendo más abundante el enrollamiento levógiro al sur de esta latitud y el dextral al norte de ésta. A la vez, este autor denomina estas formas comoN. pachyderma f. sinistralis ( $\sin$. o lev.) y $N$. pachyderma f. dextralis (dex.).

Hasta el momento, estas dos formas han sido tratadas como especies distintas debido a su hábitat diferente y a que cada una de ellas es utilizada como indicador oceanográfico debido a su comportamiento individual frente a condiciones oceanográficas, principalmente temperatura (e.g. surgencia) (Marchant et al. 1998). Debido a ésto, en el presente trabajo se ha decidido designarlas definitivamente, de acuerdo a la literatura, como especies distintas; nominándolas como Neogloboquadrina incompta (Cifelli 1961) a la forma dextral y a $N$. pachyderma (Ehrenberg 1861) a la forma levógira, esta última por el hecho a que fue la primera forma mencionada en la descripción de N. pachyderma (Ehrenberg 1861) por lo que mantiene su nominación original; y como Cifelli (1961) denomina a la forma dextral como $N$. incompta por ser secundariamente descrita por Ehrenberg (1861), se mantiene la nominación dispuesta por Cifelli. Se sugiere hacer en otro estudio 
análisis de ADN para definir si son realmente especies diferentes.

- Globigerinoides sacculifer (Brady 1877) y Globigerinoides trilobus (Reuss 1850):

Se mantienen las especies G. sacculifer y G. trilobus por encontrar caracteres suficientes para diferenciarlas entre sí, a pesar de que autores como Boltovskoy (1981), dejan como sinónimo a $G$. trilobus y G. sacculifer por creer que una representa el estadio juvenil de la otra o viceversa como indica Hemleben et al. 1989, por ser poco diferenciables en los estadios juveniles, lo cual lleva a dudar si es la misma especie, dos especies o dos simples formas para una misma especie como lo indican varios autores (Bolli 1957, Jenkins 1960, Jenkis 1971, Boltovskoy \& Watanabe 1975, Boltovskoy 1976).

En el presente trabajo se encontró que los adultos de la misma talla son fácilmente reconocidos a diferencia de los estados juveniles, donde estos últimos son casi indistinguibles y se les encontró en el mismo período de tiempo, prácticamente en las mismas muestras (viviendo conjuntamente), lo cual indica que no pueden ser subespecies. Por lo que se propone en trabajos posteriores realizar estudios de ADN y definir su estatus taxonómico.

\section{CONCLUSIONES}

Durante la Condición El Niño 1997-98 a la latitud de $30^{\circ} \mathrm{S} ; 73^{\circ} \mathrm{W}$ frente a Coquimbo, en la asociación de foraminíferos planctónicos se distinguen especies típicas de la Zona de Transición (Condición Normal) y de aguas cálidas (subtropical y tropical) (condición El Niño).

De las 26 especies encontradas en el presente estudio, 4 de ellas sufren cambios nomenclaturales:

- Neogloboquadrina pachyderma(dex.) (Ehrenberg 1861) cambia a Neogloboquadrina incompta (Cifelli 1961).

- Neogloboquadrina pachyderma(lev.) (Ehrenberg 1861) mantiene el nombre original de la especie Neogloboquadrina pachyderma (Ehrenberg 1861). - Globigerinoides sacculifer (Brady 1877) y Globigerinoides trilobus (Reuss 1850) quedan como especies diferentes.

Para condición El Niño 1997-98, en el área de
Coquimbo existen 4 especies estrictamente indicadoras de este evento: 3 principalmente por su presencia: Globigerinella aequilateralis, Globorotalia crassaformis y Pulleniatina obliquiloculata, y Neogloboquadrina dutertrei, por el aumento en su abundancia.

Durante El Niño 1997-98 se registran por primera vez 7 especies: Globigerinella digitata, Globigerinoides trilobus, Globorotalia tumida para el área de Coquimbo y condición El Niño, Globigerinoides sacculifer, Globorotalia theyeri, Hastigerina digitat y Globigerinita uvula para condición El Niño. Las 6 primeras especies recién nombradas (propias de aguas tropicales) son indicadoras de la intensidad de El Niño 1997-98 para el área de estudio.

Finalmente, el aumento de la diversidad específica en el área de estudio con nuevas especies de aguas cálidas indica que el evento El Niño de 1997-98 fue más intenso que El Niño 1991-92.

\section{AGRADECIMIENTOS}

Los autores agradecen el financiamiento de esta investigación a los proyectos Fondecyt N No1010912 y Copas $\mathrm{N}^{\circ} 150100007$, al personal del Laboratorio de Microscopía Electrónica de la Universidad de Concepción por su colaboración y paciencia en la toma de las microfotografías (SEM), así como a la Escuela de Graduados de la Universidad de Concepción por su apoyo económico.

\section{BIBLIOGRAFIA}

Akers, W. H. \& J. H. Dorman. 1964. Pleistocene Foraminifera of the Gulf Coast. Tulane Stud. Geol. 3(1):1-94.

BANDY, O. L. 1960. The geologic significance of coiling rations in the foraminifer Globigerina pachyderma (Ehrenberg). J. Paleont. 34(4):671-681.

BANDY, O. \& K. Rodolfo. 1964. Distribution of foraminifera and sediments, Peru-Chile trench area. DeepSea Research. 11:817-837.

BanNer, F. T. \& W. H. B Low. 1959. The classification and stratigraphical distribution of the Globigerinaceae. Paleontology. 2(1):1-27.

BANNER, F. T. \& W. H. BLow. 1960a. The taxonomy, morphology and affinities of the genera included in the subfamily Hastegerininae. Micropaleontology. 6(1):19-31.

B ANNER, F. T. \& W. H. B Low. 1960b. Some primary types 
of species belonging to the superfamily Globigerinaceae. Cushman Found. Foram. Res., Contr. 11(1):41 pp.

BÉ, A. W. H. 1977. An ecological, zoogeographic and taxonomic review of recent planktonic foraminifera. In: Oceanic Micropaleontology. A. T. S. Ramsay (Ed.), Academic Press, New York. 1:1-100.

Bé, A. W. H. \& D. S. Tolderlund. 1971. Distribution and ecology of living planktonic foraminifera in surface waters of the Atlantic and Indian Oceans. In: The Micropaleontology of the Oceans. B. M. Furnell \& W. R. Riedel (Eds.). Cambridge Univ. Press. 105-149.

Belford, D. J. 1962. Miocene and Pliocene planktonic Foraminifera, Papua-New Guinea. Bull. Bur. Miner. Resour. Geol. Geophys. Aust. 62(1):1-51.

Bijma, J, J. Erez \& C. Hemleben. 1990. Lunar and semilunar reproductive cycles in some spinose planktonic foraminifers. Journal of Foraminiferal Research. 20(2):117-127.

BLow, W. H. 1956. Origin and evolution of the foraminiferal genus Orbulina d'Orbigny. Micropaleontology. 2(1):57-70.

BLow, W. H. 1959. Age, correlation and biostratigraphy of the upper Tocuyo (San Lorenzo) and Pozon Formations, eastern Falcon, Venezuela. Bull. Am. Paleont. 39(178):59-251.

Bolli, H. M. 1957. Planktonic Foraminifera from the Oligocene - Miocene Cipero and Lengua Formations of Trinidad, B.W.I. Bull. U. S. Nat. Mus. 215:97123.

Boltovsкoy, E. 1976. Distribution of Recent foraminifera of the South America region In: Foraminifera. Hedley, R. H. \& C. G. Adams, (Eds). Academy Press, New York. 2:171-236.

Boltovsкoy, E. 1981. Foraminifera. In: Atlas del Zooplancton del Atlántico Suroccidental y métodos de trabajo con el zooplancton marino. Boltovskoy, D. (Ed.). Publicación Especial del INIDEP Mar del Plata, Argentina. p. 317-352.

Boltovskoy, E. \& F. TheYER. 1970. Foraminíferos recientes de Chile Central. Hidrobiología. Rev. Museo Argentino de Cs. Nat. "Bernardino Rivadavia" e Instituto Nac. de Investigación de las Cs. Naturales. 2(9):279-385.

Boltovskoy, E. \& S. Watanabe. 1975. Foraminíferos planctónicos en sedimentos del Pacífico entre Isla de Pascua y los $52^{\circ} \mathrm{S}$. Mus. Argentino Cienc. Nat., Rev. 1(8):65-77.

Boltovskoy, E. \& R. Wright. 1976. Recent Foraminifera. The Hague. 515 pp.

Boltovskoy; E. Boltovskoy, D. Correa, N. \& F. Brandini. 1996. Planktic foraminifera from the southwestern Atlantic $\left(30^{\circ}-60^{\circ} \mathrm{S}\right)$ : species-specific patterns in the upper $50 \mathrm{~m}$. Marine Micropaleontology. 28:53-72.

Brady, H. B. 1877. Supplementary note on the foraminifera of the chalk of the New Britain Group. Geol. Mag. 4(12):535-546.

BRADY, H. B. 1879. Notes on some of the reticularian Rhizopoda of the Challenger Expedition II: Addi- tions to the knowledge of porcellaneous and hyaline types. Quart. Jour. Micro. Sci, London, n. s. 19:286 pp.

Brady, H. B. 1882. Report on the foraminifera.In: Tizard \& Murray, J. (Eds.), Exploration of the Faroe Channel, during the summer of 1880, in H. M. S. Knight Errant, with subsidiary reports: Roy. Soc. Edinburgh Proc. 11(1880-1882):761pp.

BRADY, H. B. 1884. Reports on the foraminifera dredged by H.M.S. Challenger during the years 1873-1876. Rept. Voy. Challenger, Zol. 9:814 pp.

Carstens, J. \& G. Wefer. 1992. Recent distribution of planktonic foraminifera in the Nansen Basin, Arctic Ocean. Deep-Sea Research. 39(2):S507-S524.

Carter, A. N. 1959. Guide Foraminifera of the Tertiary stages in Victoria. Min. Geol. J. Aust. 6(3):48-54.

Cavalier-Smith, T. 1998. A revised six kingdom system of life. Biol. Rev. 73:203-266.

Cifelli, R. 1961. Globigerina incompta, a new species of pelagic foraminifera from the North Atlantic. Cushman Found. Foram. Res., Contr. 12(3):8386.

Cifelli, R. \& R. K. Smith. 1970. Distribution of planktonic foraminifera in the vicinity of the North Atlantic current. Smithsonian Contrib. Paleobiology. 4:52 pp.

Coloma, C., M. Marchant, D. Hebbeln \& H. González. 2002. El Niño 1997-98 a través de Foraminíferos Planctónicos frente Coquimbo, Chile. XXII Congreso de Ciencias del Mar. Resúmenes. Facultad de Ciencias, Universidad Austral de Chile. Sociedad Chilena de Ciencias del Mar. Valdivia. p. 114.

Conato, V. \& U. Follador. 1967. Globorotalia crotonensis e Globorotalia crassacrotonensis nuove specie del Pliocene italiano. Boll. Soc. Geol. Italiana. 86:555-563.

Cullen, J. \& W. Prell. 1984. Planktonic Foraminifera of the northen Indian Ocean: distribution and preservation in surface sediments. Marine Micropaleontology. 9:1-52.

Cushman, J. 1927. An outline of a re-classification of the Foraminifera. Contr. Cushman Lab. Foram. Res. 3(1):1-105.

Cushman, J. \& R. Wickenden. 1929. Recent foraminifera from off Juan Fernandez Islands. Proc. U. S. Nat. Mus. 75(9):1-16.

Cushman, J., R.E. Stewart \& K. C. Stewart. 1930. Tertiary foraminifera from Humboldt County, California. San Diego Soc. Nat. Hist., Trans. 6(2):1-77.

Decrouez, D. 1989. Generic Ranges of Foraminiferida. Revue de Paléobiologie. Genève, Suisse. 8(1):263321.

D’Orbigny. 1839. Voyage dans l'Amerique Meridionale. Foraminiféres. 5(5): 1-86 (Atlas, 9, 1847), Paris. In Gay, C. 1854. Historia Física y Política de Chile. Zoología 8 (Foraminíferos). p. 457-468.

EGGER, J. 1893. Foraminiferen aus Meeresgrundproben, gelothet von 1874 bis 1876 von S. M. Sch. Gazelle. Abhandl. Kgl. Bayer. Akad. Wiss. München, M. Ph. CI. 18(2):193-458. 
Ehrenberg, C. G. 1861. Über die Tiefgrund-Verhältnisse des Ozeans am Eingange der Davisstrasse und bei Island. K. Preuss. Akad. Wiss. Berlin, Monastsber. Jahr 1861 (1862). p. 275-315.

Ehrenberg, C. G. 1873. Mikrogeologische Studien über das kleinste Leben der Meeres-Tiefgründe aller Zonen und dessen geologischen Einfluss. K. Preuss. Akad. Wiss. Berlin, Abh. Jahr 1872. p. 131-139.

ERICson, D. 1959. Coiling direction of Globigerina pachyderma as a climatic index. Science. 130:219-220.

Fairbanks, R., P. Wiebe \& A. Bé. 1980. Vertical distribution and isotopic composition of living planktonic foraminifera in the western North Atlantic. Science. 207:61-63.

Fairbanks, R., M. Sverdlove, R. Free, P.H. Wiebe \& A. W. BÉ. 1982. Vertical distribution and isotopic fractionation of living planktonic foraminifera from the Panama Basin. Nature. 298:841-844.

Finlay, H. J. 1939. New Zealand Foraminifera: key species in stratigraphy $-\mathrm{N}^{\circ} 1$. Trans. R. Soc. N. Z. 68:504-533.

FinLay, H. J. 1947. The foraminiferal evidence for Tertiary trans-Tasman correlation. Trans. R. Soc. N. Z. 76(3):327-352.

Finlay, H. M. \& J. M ARwick . 1940. The divisions of the Upper Cretaceous and Tertiary in N. Zealand. Trans. R. Soc. N. Z. 70(1):77-135.

Fisher, G. \& G. Weber. 1991. Sampling preparation and analysis of marine particulate matter. In: The Analysis and Characterization of Marine Particles. Hurd, D. C. \& D. W. Spencer (Eds.). Geophysical Monograph. 63:391-397.

Galloway, J. \& S. WisSLER. 1927. Pleistocene foraminifera from the Lomita Quarry, Palos Verdes Hills, California. J. Paleontol. 1:35-87.

Giglio, S. 2001. Variación estacional e interanual de la composición isotópica de los foraminíferos planctónicos: Globigerina bulloides y Neogloboquadrina pachyderma (dextral) y su relación con los procesos de surgencia frente a Coquimbo, Chile. Tesis para optar al título de Oceanógrafo. Escuela de Ciencias del Mar, Facultad de Recursos Naturales, Universidad Católica de Valparaíso. 66 pp.

GuzMÁn, R. 1972. El género Globigerina en Chile y la distribución zoogeográfica de sus especies recientes (Protozoos, Foraminíferos). Noticiario Mensual Museo de Historia Natural. 16 (188):3-9.

Hebbeln, D. M. Marchant \& G. Wefer. 2000. Seasonal variations of the particle flux in the PeruChile current at $30^{\circ} \mathrm{S}$ under "normal" and "El Niño" conditions. Deep-Sea Research II (47):2101-2128.

Hemleben, C., M. Spindler \& O. R. Anderson. 1989. Modern Planktonic Foraminifera. SpringerVerlag New York Inc. 363 pp.
Heron-Allen, E. \& A. Earland. 1932. Foraminifera Pt. 1. The ice-free area of the Falkland Islands and adjacent seas. Discovery Rep. 4:291-450.

Hornibrook, N. De B. 1958. New Zealand Upper Cretaceous and Tertiary foraminiferal zones and some overseas correlations. Micropaleontology. 4(1):25-38.

Hornibrook, N. DE B. 1961. Tertiary Foraminifera from Oamaru District (N. 2) Part. 1- Systematics and distribution. N. Z. Geol. Surv. Paleont. Bull. 34(1):192 pp.

Hulme, S. G. 1964. Recent Foraminifera from Manukau Harbour, Auckland, New Zeland. N. Z. Jl. Sci. 7(3):305-40

Jenkins, D. 1960. Planktonic Foraminifera from the lakes Entrance oil shaft, Victoria, Australia. Micropaleontology. 6(4):345-71.

Jenkins, D. 1964. Location of the Pliocene-Pleistocene boundary. Contr. Cushman Found Foram. Res. 15(1):25-27.

Jenkins, D. 1971. New Zealand Cenozoic Planktonic Foraminifera. New Zealand Geol. Survey $\mathrm{Pa}$ leontological Bull. 42:278 pp.

Kemle-von MücKe, S. \& C. H emleben. 1999. Foraminifera. In South Atlantic Zooplankton. Boltovskoy, D. (Ed.). p. 43-73.

Kennett, J. \& M. S. Srinivasan. 1983. Neogene Planktonic Foraminifera A Phylogenetic Atlas. Hutchinson Ross Publishing Company. Stroudsburg, Pennsylvania. 263 pp.

Kustanowich, S. 1963. Distribution of planktonic Foraminifera in surface sediments of the south-west Pacific Ocean. N. Z. J1. Geol. Geophys. 6(4):534-565

Le Roy, L. W. 1964. Smaller Foraminifera from the late Tertiary of southern Okinawa. Prof. Pap. U. S. Geol. Surv. 454-F; F1-F58.

Loeblich, A. \& H. T appan. 1988. Foraminiferal Genera and their Classification. Van Nostrand Reinhold, New York. 970 pp.

Marchant, M. 1997. Rezente und spätquartäre Sedimentation planktischer Foraminiferen im PeruChile strom. Tesis de Doctorado. Universität Bremen, Bremen. 115 pp.

Marchant, M., Hebbeln, D. \& G. Wefer. 1998. Seasonal flux patterns of planktic foraminifera in the Peru-Chile Current. Deep-Sea Research. I 45:1161-1185.

Marchant, M., D. Hebbeln, S. Giglio, C. Coloma \& H. GonzÁlez. Seasonal and interannual variations in the flux patterns of planktic foraminifera in the Humboldt Current. Deep Sea Research. Humboldt Current System: In litteralis

McInnes, B. A. 1965. Globorotalia miozea Finlay as an ancestor of Globorotalia inflata (d'Orbigny). N. Z. J. Geol. Geophys. 8(1):104-108.

NatLand. M. L. 1938. New species of foraminifera from off the west coast. Scripps Inst. Oceanogr. Bull. 4:137-164.

PARKer, F. L. 1962. Planktonic foraminiferal species in 
Pacific sediments. Micropaleontology. 8(2):219254.

PARKer, W. K \& T. R. Jones. 1862. In Carpenter, W. B., Parker, W. K. \& T. R. Jones., Introduction to the study of the foraminifera. Roy. Soc. Publs. London. p. 1-319.

PARKeR, W. K. \& T. R. Jones. 1865. On some foraminifera from the North Atlantic and Artic Oceans, including Davis Straits and Baffin's Bay. Roy. Soc. London, Philos. Trans. 155:365-368.

Pezzani, F. 1963. Studio micropaleontologico di un campione della serie messiana di Tabiano Bagni (Parma). Riv. Ital. Paleont. Stratigr. 69(4):559662.

Reuss, A. 1850. Neue Foraminiferen aus den Schiten des osterreichischen Tertiarbeckens. Deutsche Akademie der Wissenschaften Wien. 1:365-390.

Reynolds, L. \& R. Thunell. 1986. Seasonal production and morphologic variation of Neogloboquadrina pachyderma (Ehrenberg) in the northeast Pacific. Micropaleontology. 32:1-8.

Rhumbler, L. 1911. Die Foraminiferen (Thalamophoren) der Plankton-Expedition. Erster Teil: Die allgemeinen Organisations-Verhältnisse der Foraminiferen: Ergebnisse der PlanktonExpedition der Humboldt-Stiftung (1909). 3:1-331.

Saito, T. 1963. Miocene Planktonic Foraminifera from Honshu, Japan. Sci. Rep. Tôhoku Univ., ser. 2 (Geol.). 35(2):123-209.
SAUtTer, L. \& R. Thunell. 1991. Seasonal variability in the $\mathrm{d}^{18} \mathrm{O}$ and $\mathrm{d}^{13} \mathrm{C}$ of planktonic foraminifera from an upwelling environment: sediment trap results from the San Pedro Basin, Southern California Bight. Paleocenography. 6:307-334.

Steens, T. N. F., G. Ganssen \& D. Kroon. 1992. Oxygen and carbon isotopes in planktonic foraminifera as indicators of upwelling and upwelling-induced high productivity in sediments from the northwestern Arabian Sea. In: Upwelling Systems: Evolution since the Early Miocene, C. P. Summerhayes, W. L. Prell \& K. C. Emeis (eds). Geological Society Special Publication. 64:107119.

Takayanagi, Y. \& T. Saito. 1962. Planktonic Foraminifera from the Nabori Formation, Shikoku, Japan. Sci. Rep. Tôhoku Univ., 2nd ser. (geol.), spec. 5:1-78.

Zapata, A. \& R. Castillo. 1986. Tanatocenosis de foraminíferos planctónicos sedimentados en Ba-

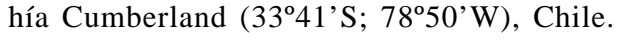
Biota, Osorno, Chile. 2:51-63.

Zapata, A. \& S. VAREla. 1975. Foraminíferos litorales

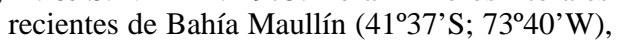
Chile. Cienc. y Nat. 16(1):14-24.

Zapata, J. \& C. CEA. 2002. Foraminíferos planctónicos del Archipiélago de Juan Fernández (3341'S; $\left.78^{\circ} 50^{\prime} \mathrm{W}\right)$, Chile. Bol. Soc. Biol. Concepción. 73:53-63. 